\title{
A população ocupada e a renda no Brasil: encontros e desencontros ${ }^{1}$
}

\author{
Lucia Silva Kubrusly ${ }^{2}$
}

\begin{abstract}
Resumo
O trabalho fornece uma análise do mercado de trabalho no Brasil, focalizando encontros entre a população ocupada e a renda, isto é, verifica em quais estados e/ou atividades ocorrem simultaneamente bons rendimentos e alta proporção de ocupação. A base de dados utilizada é a PNAD/2007, e os principais cortes utilizados são as Unidades da Federação, atividades econômicas, rendimentos mensais e população ocupada.
\end{abstract}

Palavras-chave: Mercado de trabalho; Setores da economia; Análise de dados econômicos.

\begin{abstract}
Population and income in Brazil: where do they go together?

This paper presents an analysis of the labor market in Brazil focusing the relation of population and income. We examine in which Federal Units or economic activities good wages and high occupation occur at the same time. The data base is generated from PNAD/2007, considering Federal Units, economic activities, monthly income and employed labor.
\end{abstract}

Keywords: Labor market; Economic sectors; Economic data analysis.

JEL J21, J31, R12, R23.

\section{Introdução}

O objetivo deste trabalho é fornecer um panorama da ocupação e dos rendimentos no Brasil, subdivido nas principais atividades econômicas e nas 27 Unidades da Federação. A pergunta básica que se procura responder é: onde estão os trabalhadores e onde está a renda? A origem da pergunta está na profunda diferença das condições de trabalho e vida da população ocupada brasileira. Tal diferença inclui desigualdades de renda, de oferta de trabalho, de acesso à qualificação de mão de obra, de qualidade de vida, de alimentação etc. O que se procura mostrar é que a desigualdade se dá em vários níveis, isto é, regiões desenvolvidas também apresentam desigualdades internas, que aqui poderão ser vislumbradas pelas diversas ocupações (com diferentes remunerações) presentes nestas regiões. Por outro lado, regiões reconhecidamente atrasadas também apresentam suas desigualdades internas, refletidas nas remunerações das diferentes atividades econômicas. Assim, ao contrário de outras análises da população

(1) Trabalho recebido em 05 de fevereiro de 2010 e aprovado em 23 de outubro de 2010.

(2) Professora do Instituto de Economia da Universidade Federal do Rio de Janeiro (IE/UFRJ), Rio de Janeiro, RJ, Brasil. E-mail: luciak@alternex.com.br.

Economia e Sociedade, Campinas, v. 20, n. 3 (43), p. 567-600, dez. 2011. 
ocupada brasileira, que focalizam preferencialmente as "melhores" atividades e regiões, neste trabalho, o foco são as diferenças.

Entre as diferenças observadas na sociedade brasileira, a desigualdade de renda talvez seja a mais estudada. Recentemente, diversos trabalhos procuram analisar a atual queda da desigualdade de renda no Brasil. Ferreira et al. (2006) estudaram a evolução de medidas de concentração de renda no período de 1981 até 2004. Os autores mostram que, nos anos mais recentes, há queda na desigualdade. Entre os fatores que explicariam esses resultados, são sugeridos a queda da inflação (após 1993) e, mais recentemente, os programas governamentais de transferência de renda (após 2001). Analisando ainda a mesma questão no período 1997-2004, Hoffman (2006) conclui que, embora a renda média real da população tenha reduzido $5,5 \%$, a renda média entre os $40 \%$ mais pobres aumentou cerca de $11 \%$ no período considerado. Outra análise mais recente está em Hoffmann e Ney (2008), onde são comparadas informações das Contas Nacionais, segundo as quais a desigualdade não foi reduzida, e da Pesquisa Nacional por Amostra de Domicílio, segundo a qual a desigualdade foi reduzida no mesmo período. Os autores discutem em profundidade os possíveis motivos dessa discrepância.

Com uma visão alternativa às análises de concentração de renda, a abordagem adotada no presente trabalho baseia-se nas diferenças no nível de ocupação e no nível de renda em diferentes regiões brasileiras e diversas atividades econômicas. A principal hipótese levantada é que há forte heterogeneidade nos níveis de emprego e salários entre regiões, entre atividades econômicas e também intrarregiões e intra-atividades econômicas. É nessa realidade desigual que ocorrem encontros e desencontros entre a população ocupada e a renda.

\section{Panorama nacional}

A base de dados utilizada será a Pesquisa Nacional por Amostra de Domicílio (PNAD/IBGE), ano 2007. Foram observados os valores da população ocupada e rendimento mensal médio, considerando-se as 27 Unidades da Federação e as seguintes atividades econômicas, definidas na PNAD:

Administração Pública - administração pública, defesa e seguridade social.

Indústria - indústria de transformação e indústria extrativa.

Construção civil.

Comércio e reparação.

Agricultura - agricultura, pecuária, silvicultura, exploração florestal, pesca e aqüicultura. 
Serviços (subdividido em seis atividades) ${ }^{3}$ :

Educação, Saúde, Serviços sociais.

Serviços domésticos.

Outras atividades - Intermediação financeira, Seguros e previdência privada, Atividades imobiliárias, Aluguel de veículos e máquinas, Atividades de informática, $P \& D$, Serviços prestados a empresas, Organismos internacionais.

Transportes, armazenagens, e comunicação.

Outros serviços coletivos, sociais e pessoais - Limpeza urbana, Atividades associativas, Atividades recreativas culturais $e$ desportivas, Serviços pessoais.

Alojamento e Alimentação.

Nosso primeiro olhar será sobre a população ocupada brasileira distribuída nas diferentes atividades econômicas. A Tabela 1 fornece a proporção da população ocupada e o rendimento mensal médio para cada atividade econômica.

Tabela 1

Brasil - Ocupação e renda nas 11 atividades econômicas

\begin{tabular}{l|c|c}
\hline Atividade Econômica & $\begin{array}{c}\text { Renda Mensal } \\
\text { Média (R\$) }\end{array}$ & $\begin{array}{c}\text { Proporção da } \\
\text { População } \\
\text { Ocupada }\end{array}$ \\
\hline Administração pública & 1554 & 0,050 \\
\hline Indústria & 1007 & 0,153 \\
\hline Construção civil & 813 & 0,067 \\
\hline Comércio e reparação & 946 & 0,180 \\
\hline Agricultura, Pecuária, Silvicultura,... & 661 & 0,183 \\
\hline Serviços: & 995 & 0,367 \\
\hline Educação, Saúde, Serviços Sociais & 1189 & 0,093 \\
\hline Serviços domésticos & 346 & 0,074 \\
\hline Intermediação Financeira, Imobiliária,... & 1452 & 0,074 \\
\hline Transportes, armazenagens... & 1220 & 0,048 \\
\hline Outros Serviços coletivos... & 878 & 0,041 \\
\hline Alojamento e Alimentação & 733 & 0,037 \\
\hline Brasil & 943 & 1,00 \\
\hline
\end{tabular}

(em itálico, as subdivisões do setor de serviços).

Elaboração própria a partir dos dados da PNAD (2007).

Destas informações, pode-se destacar as atividades "Administração Pública", com maior valor para renda (1554 reais), correspondendo a $5 \%$ da população ocupada, e também "Intermediação Financeira, Imobiliária,...", com renda mensal média de 1452 reais, ocupando 7,4\% da população. No extremo

(3) Aqui são apresentadas as atividades com os nomes adotados na PNAD. No decorrer do trabalho, no entanto, algumas delas serão renomeadas visando melhor identificar as atividades incluídas em cada classificação. 
oposto, destacam-se "Serviços domésticos" e "Agricultura,..", com os menores valores de renda (346 reais e 661 reais), associados a 7,4\% e 18,3\% da população ocupada, respectivamente .

Um diagrama de dispersão é apresentado na Figura 1, representando a renda mensal média e a proporção da população ocupada nas onze atividades econômicas.

Figura 1

Diagrama de dispersão: renda e proporção da ocupação em 11 atividades econômicas

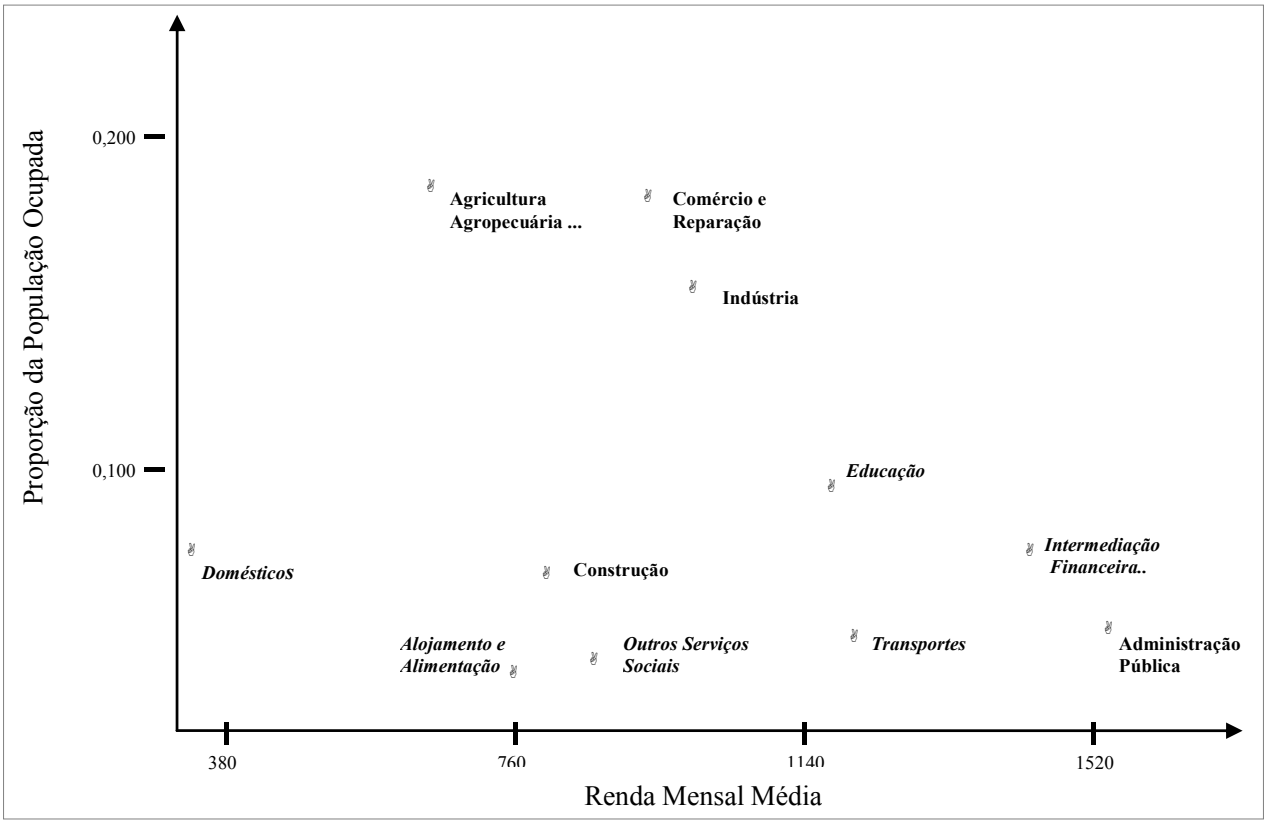

Este gráfico mostra nitidamente a maior dispersão para valores mais baixos de renda. Isto é, valores baixos de renda incluem atividades com alta e baixa participação na ocupação; valores altos de renda correspondem a atividades com baixa participação na ocupação. Em outras palavras, segundo o corte por ora adotado, não há atividades com altos rendimentos médios que incluam uma grande proporção da população ocupada, tornando evidente o primeiro desencontro entre a renda e a população ocupada.

De acordo com a Tabela 1, três atividades se destacam no que se refere ao volume de emprego: "Agricultura...", com 18,3\% da ocupação; "Comércio e reparação", com 18,0\% das ocupações; "Indústria”, com 15,3\% das ocupações no Brasil. Essas três atividades, no entanto, têm comportamentos diferentes se olharmos suas distribuições nas Unidades da Federação. Enquanto "Comércio e reparação" é bastante presente em quase todas as Unidades (oscilando entre 10\% 
e $20 \%$ da população ocupada), a distribuição das ocupações em "Agricultura..." não é de modo algum uniforme. Tome-se, por exemplo, o Maranhão e o Piauí, que apresentam cerca de $40 \%$ da ocupação nesta atividade, e, no extremo oposto, Rio de Janeiro e Distrito Federal, com cerca de apenas 2\% das ocupações em "Agricultura...". Ainda, a atividade industrial também varia significativamente de acordo com a Unidade da Federação, representando 26\% das ocupações em São Paulo e apenas 5,1\% no Distrito Federal. De qualquer forma, essas três atividades em conjunto representam metade $(51,1 \%)$ da população ocupada no Brasil. A outra metade está distribuída entre as oito atividades restantes. Por isso, antes de passarmos à análise regional, que descreverá melhor a situação da população ocupada no país, vamos nos deter um momento nessas três atividades.

O setor agropecuário no Brasil apresenta forte contraste no que se refere às características da ocupação e da organização da produção. Por um lado, a agropecuária de subsistência, intensiva em mão de obra, de característica familiar, levada adiante por uma população muito pobre, que muitas vezes não recebe qualquer renda por seu trabalho, e, por outro lado, grandes empreendimentos agrícolas desenvolvendo atividades intensivas em capital, com alta produtividade. Perobelli, Almeida, Alvim e Ferreira (2007), analisaram a produtividade do setor agrícola brasileiro nos anos 1991, 1997 e 2003 para 558 microrregiões brasileiras. Constataram que:

...em geral, microrregiões com alta produtividade agrícola são vizinhas de outras microrregiões na mesma situação, o mesmo ocorrendo com microrregiões com baixa produtividade agrícola, que também são vizinhas de outras microrregiões com essas características. Ademais, essa autocorrelação espacial da produtividade agrícola mostra-se crescente nos três momentos de tempo analisados, tanto global quanto localmente.

Essas conclusões corroboram nossa posição, segundo a qual os contrastes no desenvolvimento social ocorrem em toda parte e ao longo do tempo, e, segundo ainda os mesmos autores, as diferenças não estão diminuindo no tempo, pelo contrário, ao menos no setor agrícola.

A atividade industrial também apresenta fortes contrastes, com setores avançados, como, por exemplo, eletrônica, telecomunicações, produtos químicos, ao lado de setores mais tradicionais, tais como cerâmica, vestuário, mobiliário etc. As diferenças no desenvolvimento das divisões da indústria foram analisadas por Saboia e Kubrusly (2008), cujo trabalho apresenta índices de desenvolvimentos para 27 divisões da indústria no Brasil e nas cinco grandes regiões geográficas. Segundo esses índices, estão entre as divisões mais desenvolvidas: Extração de petróleo e serviços relacionados, Fabricação de máquinas para escritório e equipamentos de informática, Fabricação de material eletrônico, entre outros. Entre os menos desenvolvidos estão: Fabricação de artefatos de couro e calçados, 
Extração de minerais não metálicos, Fabricação de produtos de madeira. As conclusões apontam para as diferenças regionais e setoriais:

Com relação aos resultados empíricos, verificou-se que a indústria continua apresentando forte heterogeneidade regional. Os dados confirmam a superioridade da região sudeste relativamente ao restante do país. .... Também em termos setoriais, as diferenças são marcantes.

A atividade de Comércio e reparação, segundo informações da PNAD/2007, ocorre intensamente em todas as Unidades da Federação. Segundo a Pesquisa Anual do Comércio (IBGE/2006), as atividades neste setor são classificadas em três segmentos: Atacadista, Varejista e Veículos, peças e motocicletas, esse último incluindo atividades no atacado e varejo. As informações disponíveis permitem calcular a razão entre "Salários e outras remunerações" e "população ocupada" nos três segmentos.

Tabela 2

Remuneração e população ocupada nos três segmentos do comércio

\begin{tabular}{l|c|c}
\hline & $\begin{array}{c}\text { Remuneração* } \\
\text { (milhares de reais) }\end{array}$ & $\begin{array}{c}\text { População ocupada } \\
(\%)\end{array}$ \\
\hline Atacadista & 13,381 & 15 \\
\hline Varejista & 6,908 & 76 \\
\hline Veículos & 9,464 & 9 \\
\hline Total & 8,108 & 100 \\
\hline
\end{tabular}

(*) Remuneração = Salários e outras remunerações / população ocupada Elaboração própria a partir da Pesquisa Anual do Comércio (IBGE/2006).

Observa-se que a menor remuneração ocorre no comércio varejista, que corresponde a $76 \%$ das ocupações no comércio. Por outro lado, a maior remuneração ocorre no comércio atacadista com apenas $15 \%$ das ocupações. Portanto, embora a atividade do comércio esteja bastante presente em todo o país, o nível de remuneração varia bastante segundo o segmento considerado. Novamente, o desencontro entre boas remunerações e a população ocupada pode ser observado.

\section{Panorama regional}

Nesta seção, a população ocupada e seu rendimento médio serão examinados, considerando também as características regionais. Para tal, serão analisadas as distribuições da ocupação e a renda média mensal nas onze atividades econômicas em cada Unidade da Federação (UF). A Tabela 3 mostra os rendimentos médios e a ocupação nas vinte e sete UFs. 
Tabela 3

Renda média mensal e ocupação nas 27 UFs

\begin{tabular}{|c|c|c|c|}
\hline UF & $\begin{array}{c}\text { Renda Média Mensal } \\
\qquad(\mathrm{R} \$)\end{array}$ & $\begin{array}{c}\text { Ocupação } \\
\text { (em milhares) }\end{array}$ & $\begin{array}{c}\text { Proporção da } \\
\text { ocupação }\end{array}$ \\
\hline RO & 832 & 775 & 0,009 \\
\hline $\mathrm{AC}$ & 921 & 306 & 0,003 \\
\hline $\mathrm{AM}$ & 849 & 1.337 & 0,015 \\
\hline RR & 758 & 193 & 0,002 \\
\hline $\mathrm{PA}$ & 725 & 3.170 & 0,035 \\
\hline AP & 904 & 251 & 0,003 \\
\hline TO & 766 & 667 & 0,007 \\
\hline MA & 583 & 2.885 & 0,032 \\
\hline PI & 546 & 1.574 & 0,017 \\
\hline $\mathrm{CE}$ & 554 & 3.850 & 0,043 \\
\hline $\mathrm{RN}$ & 690 & 1.403 & 0,016 \\
\hline PB & 653 & 1.554 & 0,017 \\
\hline $\mathrm{PE}$ & 618 & 3.606 & 0,040 \\
\hline $\mathrm{AL}$ & 670 & 1.274 & 0,014 \\
\hline SE & 667 & 927 & 0,010 \\
\hline BA & 607 & 6.461 & 0,071 \\
\hline MG & 849 & 9.812 & 0,108 \\
\hline ES & 930 & 1.696 & 0,019 \\
\hline RJ & 1.135 & 6.947 & 0,077 \\
\hline SP & 1.216 & 20.334 & 0,225 \\
\hline PR & 1.087 & 5.544 & 0,061 \\
\hline $\mathrm{SC}$ & 1.127 & 3.323 & 0,037 \\
\hline $\mathrm{RS}$ & 1.007 & 5.881 & 0,065 \\
\hline MS & 1.028 & 1.188 & 0,013 \\
\hline MT & 934 & 1.420 & 0,016 \\
\hline GO & 946 & 2.924 & 0,032 \\
\hline $\mathrm{DF}$ & 1.971 & 1.154 & 0,013 \\
\hline BR & 943 & 90.457 & 1,00 \\
\hline
\end{tabular}

Elaboração própria a partir dos dados da PNAD (2007).

Observa-se que vinte e uma das vinte e sete UFs apresentam proporção da ocupação menor que $0,05(5 \%)$. As seis UFs com maior representatividade concentram $60,7 \%$ da ocupação no país. A Figura 2 apresenta o diagrama de dispersão da renda média e proporção da ocupação.

A Figura 2 mostra que a maior parte das Unidades da Federação (dezoito UFs) apresenta baixa renda (menos de 1000 reais) e baixa ocupação (menos de 5\% da população ocupada). Duas unidades se comportam de forma muito diferente das demais: São Paulo, com mais alto percentual de ocupação $(22,5 \%$, sendo o segundo colocado o Estado de Minas Gerais com 10,8\%) e Distrito Federal com maior renda média (1971 reais, segundo colocado, São Paulo, com 1216 reais). 
Figura 2

Diagrama de dispersão: renda e proporção da ocupação nas 27 Unidades da Federação

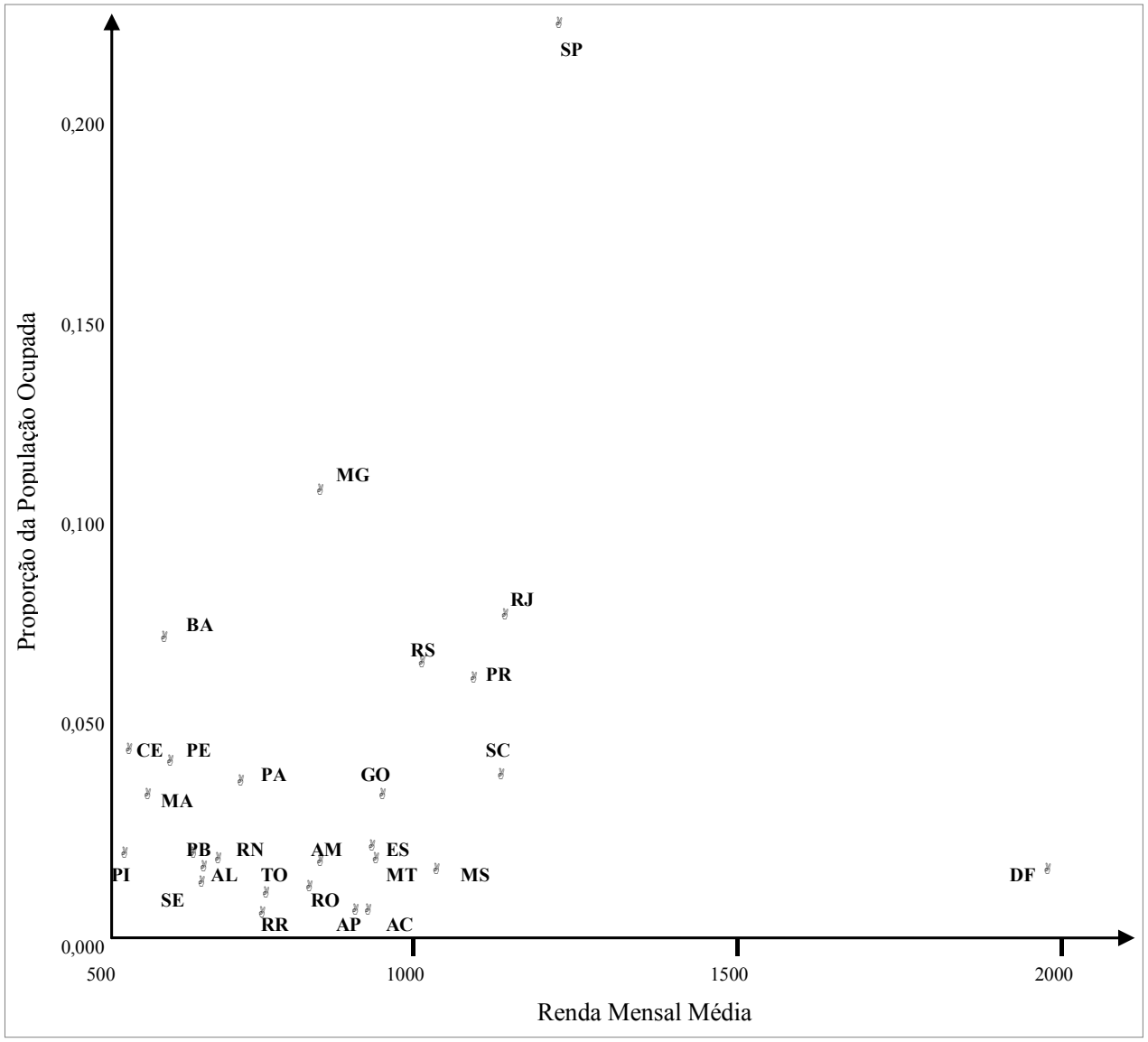

As maiores rendas (acima de 1000 reais) ocorrem no Distrito Federal, São Paulo, Rio de Janeiro, Santa Catarina, Paraná, Mato Grosso do Sul e Rio Grande de Sul. As maiores taxas de ocupações (mais que $5 \%$ da população ocupada no país) ocorrem em São Paulo, Minas Gerais, Rio de Janeiro, Bahia, Rio Grande de Sul e Paraná. Na interseção desses dois conjuntos estão o Estado de São Paulo, Rio de Janeiro, Paraná e Rio Grande do Sul. Estes são os estados que concentram mais de $5 \%$ da população ocupada e que apresentam renda média mensal maior que 1000 reais. Pode-se dizer que, nesses quatro estados, ocorre o encontro da população ocupada e da renda e, nos outros vinte e três estados, ocorrem os desencontros. Neste caso, o encontro se dá na Região Sul e Sudeste e o desencontro nas demais regiões.

A análise prossegue, incluindo as onze atividades econômicas, a distribuição das ocupações nas Unidades da Federação e os rendimentos médios. A distribuição das ocupações será analisada em primeiro lugar. 


\section{0 ponto de vista da população ocupada}

A classificação das ocupações pelas atividades econômicas e Unidades da Federação implica em duas análises possíveis: uma, que se baseia na distribuição das ocupações nas onze atividades para cada Unidade da Federação, (isto é, a análise de vinte e sete distribuições das ocupações nas atividades) e outra, baseada na distribuição das ocupações nas vinte e sete Unidades para cada atividade (isto é, a análise de onze distribuições das ocupações nas Unidades da Federação). As duas análises se completam e permitem estabelecer uma ligação entre atividades econômicas e Unidades da Federação, como será mostrado mais adiante. A distribuição da população ocupada nas onze atividades econômicas em cada Unidade da Federação encontra-se no Anexo 1 deste artigo. Esses dados permitem avaliar a importância das atividades em cada Unidade da Federação.

Conforme adiantamos na seção anterior, as proporções das ocupações em algumas atividades variam substancialmente nos diferentes estados. Começando pelas atividades da Agricultura, Indústria e Comércio, que, como mencionado, representam 51\% das ocupações no Brasil, pode-se observar que o peso da "Agricultura, pecuária, silvicultura..." é muito alto nas regiões Norte (exceto Amapá) e Nordeste e alto nas regiões Sul e Centro-Oeste. Já "Indústria" representa mais que $10 \%$ das ocupações em dezenove UFs, sendo que os maiores pesos estão no Sudeste e no Sul. A atividade "Comércio e reparação" é bastante presente em todas as Unidades da Federação, não apresentando variação significativa, embora seja possível destacar Amapá e Pará com mais de 20\% de suas ocupações nessa atividade. Nas demais atividades, os valores apresentados não são muito altos mas, tomando-se como referência a distribuição dos empregos nas onze atividades para o Brasil (ultima linha da tabela do Anexo 1), chama atenção as atividades: "Administração Pública", que apresenta altos valores no Distrito Federal, Acre e Roraima; "Educação,...”, que apresenta altos valores no Acre, Amapá, Rio de Janeiro e Distrito Federal; "Intermediações Financeiras, imobiliárias ...", que apresenta altos valores no Rio de Janeiro, São Paulo e Distrito Federal; "Serviços domésticos", que apresenta o máximo valor no Distrito Federal e o mínimo em Santa Catarina.

As informações contidas no Anexo 1 encontram-se resumidas no Quadro 1, a seguir. Estão assinaladas apenas as atividades mais importantes em cada UF.

É considerada atividade importante a que corresponde a $10 \%$ ou mais da população ocupada na UF. Os valores entre parênteses, na primeira coluna, fornecem o percentual da ocupação correspondente às atividades destacadas. 
Quadro 1

Atividades mais importantes em cada UF

\begin{tabular}{|c|c|c|c|c|c|c|c|c|c|c|c|}
\hline $\begin{array}{c}\text { UF } \\
\text { (\% da ocupação } \\
\text { coberto pelas } \\
\text { atividades } \\
\text { selecionadas) }\end{array}$ & $\frac{\sqrt[T]{3}}{\frac{E}{E}}$ & 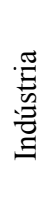 & ن & 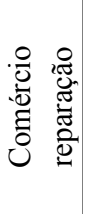 & 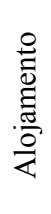 & 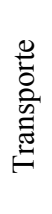 & 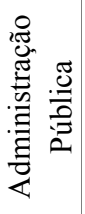 & 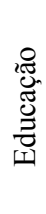 & 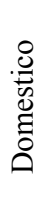 & 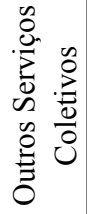 & 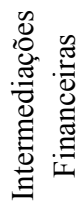 \\
\hline RO (58) & $\S \S$ & $\S$ & & $\S$ & & & & & & & \\
\hline $\mathrm{AC}(75)$ & $\S$ & $\S$ & & $\S$ & & & $\S$ & $\S$ & & & \\
\hline AM (52) & $\S$ & $\S$ & & $\S$ & & & & & & & \\
\hline RR (64) & $\S$ & & & $\S$ & & & $\S$ & $\S$ & & & \\
\hline PA (56) & $\S$ & $\S$ & & $\S$ & & & & & & & \\
\hline AP (57) & & & $\S$ & $\S$ & & & $\S$ & $\S$ & & & \\
\hline TO (56) & $\S \S$ & & & $\S$ & & & & $\S$ & & & \\
\hline MA (57) & $\S \S$ & & & $\S$ & & & & & & & \\
\hline PI (57) & $\S \S$ & & & $\S$ & & & & & & & \\
\hline CE (62) & $\S$ & $\S$ & & $\S$ & & & & & & & \\
\hline RN (55) & $\S$ & $\S$ & & $\S$ & & & & $\S$ & & & \\
\hline PB (55) & $\S$ & $\S$ & & $\S$ & & & & & & & \\
\hline PE (57) & $\S$ & $\S$ & & $\S$ & & & & & & & \\
\hline $\mathrm{AL}(52)$ & $\S \S$ & & & $\S$ & & & & & & & \\
\hline SE (63) & $\S$ & $\S$ & & $\S$ & & & & $\S$ & & & \\
\hline $\mathrm{BA}(51)$ & $\S$ & & & $\S$ & & & & & & & \\
\hline MG (53) & $\S$ & $\S$ & & $\S$ & & & & & & & \\
\hline ES (53) & $\S$ & $\S$ & & $\S$ & & & & & & & \\
\hline RJ (56) & & $\S$ & & $\S$ & & & & $\S$ & & & $\S$ \\
\hline SP (63) & & $\S$ & & $\S$ & & & & $\S$ & & & $\S$ \\
\hline PR (62) & $\S$ & $\S$ & & $\S$ & & & & $\S$ & & & \\
\hline $\mathrm{SC}(58)$ & $\S$ & $\S$ & & $\S$ & & & & & & & \\
\hline RS (57) & $\S$ & $\S$ & & $\S$ & & & & & & & \\
\hline MS (59) & $\S$ & $\S$ & & $\S$ & & & & & $\S$ & & \\
\hline MT (57) & $\S$ & $\S$ & & $\S$ & & & & & & & \\
\hline GO (48) & $\S$ & $\S$ & & $\S$ & & & & & & & \\
\hline DF (72) & & & & $\S$ & & & $\S$ & $\S$ & $\S$ & & $\S$ \\
\hline
\end{tabular}

$\S$ valores entre $10 \%$ e $29 \%$; $\S \S$ valores iguais ou maiores que $30 \%$.

Como se esperava, as atividades de maior destaque são "Agricultura, pecuária.", "Indústria" e "Comércio e reparação", sendo esta última relevante em todas as Unidades da Federação. "Educação,...” destaca-se em nove Unidades e "Administração Pública" em quatro Unidades. O percentual do emprego coberto pelas atividades selecionadas varia entre $48,4 \%$ em Goiás e $74,9 \%$ no Acre, embora, na maior parte delas, não estejam destacadas mais que três atividades. Diante da forte presença da atividade agropecuária no país, chama atenção quatro estados que não apresentam essa atividade entre as de maior 
importância: Amapá, Rio de Janeiro, São Paulo, Distrito Federal. Estes são também estados com maior diversificação nas atividades econômicas, contrastando com Maranhão, Piauí, Alagoas, Bahia, todos com apenas duas atividades em destaque: "Agricultura, pecuária" e "Comércio e reparação", sendo que Maranhão, Piauí e Alagoas apresentam mais de $30 \%$ da população ocupada em "Agricultura, pecuária". Porém, a oposição entre agropecuária e diversidade nem sempre é observada; veja, por exemplo, Acre, Roraima, Rio Grande do Norte, Sergipe, Paraná, Mato Grosso do Sul, que apresentam no mínimo quatro atividades em destaque, sendo "Agricultura, pecuária” uma delas. É de se notar, também, a ausência, no Quadro 1, das atividades "Alojamento e alimentação", "Transportes..." e "Outros serviços coletivos", indicando que estas atividades não estão entre as mais importantes (isto é, não chegam a empregar $10 \%$ da população ocupada) em qualquer das vinte e sete Unidades da Federação.

A segunda parte da análise das ocupações focalizará as distribuições da ocupação nas Unidades da Federação para cada atividade. O Anexo 2 apresenta a proporção da ocupação por Unidade da Federação para cada atividade econômica. Aqui, pode-se avaliar o peso da Unidade em cada atividade. Comparando com a distribuição da população ocupada nas Unidades da Federação no Brasil (última coluna à direita), chama atenção, entre outros, a concentração das atividades agropecuárias no Maranhão, Piauí, Ceará, Bahia, que, juntos, respondem por 35\% destas ocupações, e a alta concentração de "Intermediações financeiras, imobiliárias..." em São Paulo e Rio de Janeiro (que, juntos, correspondem a 46\% das ocupações nesta atividade).

A fim de destacar os resultados mais relevantes foi construído o Quadro 2, onde figuram apenas as Unidades da Federação mais relevantes para cada atividade. Os valores destas distribuições são, em geral, mais baixos que aqueles apresentados no Anexo 1, entre outras coisas, devido ao fato de, aqui, referirmonos às vinte e sete Unidades, enquanto, no Anexo 1, a apenas onze atividades. Por isso, o Quadro 2, a seguir, considera importante apenas as Unidades da Federação que apresentam ao menos $4 \%$ da população ocupada na referida atividade. Os valores entre parênteses, na primeira linha, fornecem o percentual das ocupações coberto pelas Unidades assinaladas.

Algumas atividades estão espalhadas pelas 4 ou 5 regiões geográficas brasileiras, outras estão visivelmente concentradas. Entre as primeiras, observa-se que são 11 as UFs importantes para “Agricultura, pecuária,...” e estão presentes nas regiões Norte, Nordeste, Sudeste e Sul, mostrando a importância desta atividade em todo o país. Outras atividades que apresentam importância em quatro das cinco regiões geográficas do Brasil são: "Construção civil", "Comércio e reparação", "Alojamento e alimentação", "Administração pública” e "Serviços domésticos". 
Quadro 2

Unidades da Federação mais importantes em cada atividade

\begin{tabular}{|c|c|c|c|c|c|c|c|c|c|c|c|}
\hline UF & 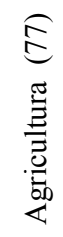 & 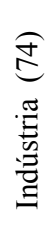 & 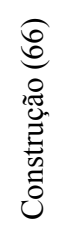 & 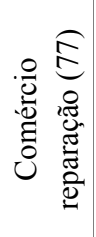 & 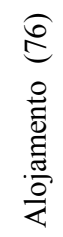 & 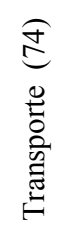 & 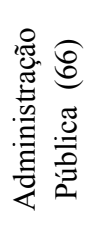 & 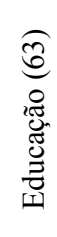 & 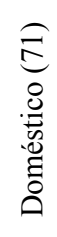 & 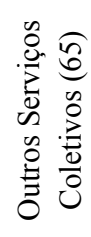 & 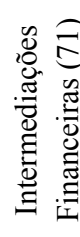 \\
\hline \multicolumn{12}{|l|}{ RO } \\
\hline \multicolumn{12}{|l|}{$\mathrm{AC}$} \\
\hline \multicolumn{12}{|l|}{$\mathrm{AM}$} \\
\hline \multicolumn{12}{|l|}{$\mathrm{RR}$} \\
\hline PA & $\S$ & & $\S$ & $\S$ & $\S$ & & $\S$ & & & & \\
\hline \multicolumn{12}{|l|}{ AP } \\
\hline \multicolumn{12}{|l|}{ TO } \\
\hline MA & $\S$ & & & & & & & & & & \\
\hline PI & $\S$ & & & & & & & & & & \\
\hline $\mathrm{CE}$ & $\S$ & $\S$ & & $\S$ & $\S$ & & & & $\S$ & & \\
\hline \multicolumn{12}{|l|}{$\mathrm{RN}$} \\
\hline \multicolumn{12}{|l|}{ PB } \\
\hline $\mathrm{PE}$ & $\S$ & & & $\S$ & $\S$ & $\S$ & $\S$ & & & & \\
\hline \multicolumn{12}{|l|}{$\mathrm{AL}$} \\
\hline \multicolumn{12}{|l|}{ SE } \\
\hline BA & $\S \S$ & & $\S$ & $\S$ & $\S$ & $\S$ & $\S$ & $\S$ & $\S$ & $\S$ & $\S$ \\
\hline MG & $\S \S$ & $\S \S$ & $\S \S$ & $\S \S$ & $\S \S$ & $\S \S$ & $\S \S$ & $\S \S$ & $\S \S$ & $\S \S$ & $\S \S$ \\
\hline \multicolumn{12}{|l|}{ ES } \\
\hline $\mathrm{RJ}$ & & $\S$ & $\S$ & $\S$ & $\S \S$ & $\S \S$ & $\S \S$ & $\S \S$ & $\S$ & $\S \S$ & $\S \S$ \\
\hline SP & $\S$ & $\S \S$ & $\S \S$ & $\S \S$ & $\S \S$ & $\S \S$ & $\S \S$ & $\S \S$ & $\S \S$ & $\S \S$ & $\S \S$ \\
\hline PR & $\S$ & $\S$ & $\S$ & $\S$ & $\S$ & $\S$ & $\S$ & $\S$ & $\S$ & $\S$ & $\S$ \\
\hline $\mathrm{SC}$ & $\S$ & $\S$ & & $\S$ & & $\S$ & & & & & \\
\hline RS & $\S$ & $\S$ & $\S$ & $\S$ & $\S$ & $\S$ & $\S$ & $\S$ & $\S$ & $\S$ & $\S$ \\
\hline \multicolumn{12}{|l|}{ MS } \\
\hline \multicolumn{12}{|l|}{ MT } \\
\hline GO & & & $\S$ & & & & $\S$ & & $\S$ & & \\
\hline DF & & & & & & & & & & & \\
\hline
\end{tabular}

$\S$ valores entre $4 \%$ e $9 \%$; $\S \S$ valores iguais ou maiores que $10 \%$.

Por outro lado, as atividades que apresentam concentração regional são "Indústria", "Transportes,...", "Educação,...", “Outros serviços coletivos" e "Intermediação Financeira, Imobiliária,...”, que situam-se, principalmente, no sudeste do país.

Chama especial atenção "Serviços domésticos" que, conforme informa a Tabela 1, é a atividade com mais baixa renda, (346 reais, sendo o segundo pior valor igual a 661 reais, observado na agricultura) e inclui oito UFs importantes, sendo cinco delas nas regiões Sudeste e Sul, as mais ricas do país. Essa atividade, 
que corresponde a 7,4\% das ocupações, é a que melhor demonstra a desigualdade social no Brasil. Na verdade, essas informações são compatíveis com a hipótese de que ao sair das regiões mais pobres do país em busca de melhores rendas, muitos trabalhadores apenas encontram colocação como empregados domésticos, atividade, esta, que pior remunera em todas as Unidades da Federação. A confirmação desta hipótese depende de outras pesquisas e não será levada adiante neste trabalho. Porém, caso fosse confirmada, seria mais um desencontro entre a renda e a população ocupada.

Ainda na análise do Quadro 2, verifica-se a ausência de catorze UFs. Estas, especificamente, não são importantes (segundo o critério aqui utilizado, isto é, corresponder à proporção da ocupação na atividade menor que 4\%) para qualquer das atividades econômicas aqui incluídas. São elas: Rondônia, Acre, Amazonas, Roraima, Amapá, Tocantins, Rio Grande do Norte, Paraíba, Alagoas, Sergipe, Espírito Santo, Mato Grosso do Sul, Mato Grosso e Distrito Federal. Note-se que a maior participação na ocupação ocorre no Espírito Santo com 1,9\% das ocupações do país.

\subsection{Fazendo as ligações entre as atividades e as Unidades da Federação}

A análise das tabelas dos Anexos 1 e 2 fornecem duas informações que podem ser associadas. A primeira destaca a importância da atividade econômica na UF e a segunda indica a importância da UF na atividade econômica. Uma leitura conjunta dos Quadros 1 e 2 permite apontar para os pares (UF, atividade) que aparecem como relevantes nos dois quadros. Cada par assinalado informa que a atividade é importante para a UF e vice-versa. O Quadro 3 mostra essas ligações.

Observa-se que estão assinaladas apenas doze UFs e cinco atividades econômicas. Mais uma vez, destacam-se "Agricultura, pecuária,...", "Indústria”, "Comércio e reparação", apresentando forte correspondência com as UFs, isto é, onde estas atividades são importantes, as UFs também são importantes para elas. É ainda possível destacar, no Quadro 3, quatro padrões de associação. Maranhão e Piauí associados à “Agricultura, pecuária,...”; Pará e Pernambuco associados à "Agricultura, pecuária,..." e "Comércio e reparação"; Ceará, Minas Gerais, Santa Catarina e Rio Grande do Sul associados à "Agricultura, pecuária,...", "Indústria" e "Comércio e reparação"; Rio de Janeiro e São Paulo associados a "Indústria", "Comércio e reparação", "Educação" e "Intermediações financeiras...". O único estado que não se enquadra em nenhum dos quatro padrões é o Paraná, associado à "Agricultura, pecuária,...", "Indústria”, , "Comércio e reparação" e "Educação". 
Quadro 3

Obtido a partir da interseção dos Quadros 1 e 2

\begin{tabular}{|c|c|c|c|c|c|c|c|c|c|c|c|}
\hline UF & 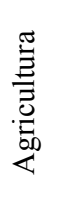 & 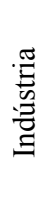 & 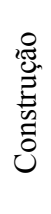 & 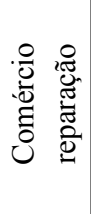 & $\begin{array}{l}\stackrel{0}{0} \\
\frac{0}{0} \\
\frac{\pi}{0} \\
\frac{\pi}{2}\end{array}$ & 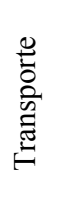 & 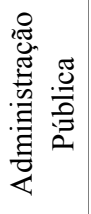 & 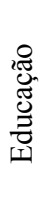 & 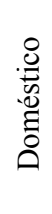 & 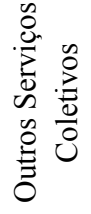 & 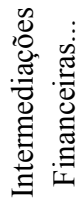 \\
\hline \multicolumn{12}{|l|}{ RO } \\
\hline \multicolumn{12}{|l|}{$\mathrm{AC}$} \\
\hline \multicolumn{12}{|l|}{$\mathrm{AM}$} \\
\hline \multicolumn{12}{|l|}{$\mathrm{RR}$} \\
\hline PA & $*$ & & & $*$ & & & & & & & \\
\hline \multicolumn{12}{|l|}{ AP } \\
\hline \multicolumn{12}{|l|}{ TO } \\
\hline MA & $*$ & & & & & & & & & & \\
\hline PI & $*$ & & & & & & & & & & \\
\hline $\mathrm{CE}$ & $*$ & $*$ & & $*$ & & & & & & & \\
\hline \multicolumn{12}{|l|}{ RN } \\
\hline \multicolumn{12}{|l|}{ PB } \\
\hline PE & $*$ & & & $*$ & & & & & & & \\
\hline \multicolumn{12}{|l|}{$\mathrm{AL}$} \\
\hline \multicolumn{12}{|l|}{ SE } \\
\hline BA & $*$ & & & $*$ & & & & & & & \\
\hline MG & $*$ & $*$ & & $*$ & & & & & & & \\
\hline \multicolumn{12}{|l|}{ ES } \\
\hline RJ & & $*$ & & $*$ & & & & $*$ & & & $*$ \\
\hline SP & & $*$ & & $*$ & & & & $*$ & & & $*$ \\
\hline PR & $*$ & $*$ & & $*$ & & & & $*$ & & & \\
\hline $\mathrm{SC}$ & $*$ & $*$ & & $*$ & & & & & & & \\
\hline $\mathrm{RS}$ & $*$ & $*$ & & $*$ & & & & & & & \\
\hline \multicolumn{12}{|l|}{ MS } \\
\hline \multicolumn{12}{|l|}{ MT } \\
\hline \multicolumn{12}{|l|}{ GO } \\
\hline DF & & & & & & & & & & & \\
\hline
\end{tabular}

* atividade importante para a UF e UF importante para atividade.

\subsection{Analisando semelhanças e diferenças}

Os Quadros 1 e 2 fornecem uma visão simplificada dos dados apresentados nos Anexos 1 e 2, pois foram descartados diversos valores para suas construções. Outra maneira de analisar os dados destas tabelas, reduzindo a perda de informação, é realizar uma Análise de Grupamento. Uma abordagem detalhada desta técnica de análise estatística pode ser encontrada em Mingoti (2007), e uma aplicação em economia pode ser encontrada em Kubrusly e Saboia (2006). Trata- 
se de técnica de análise multivariada, tendo como objetivo encontrar objetos semelhantes, segundo certo critério.

A seguir serão realizadas duas Análises de Grupamento, uma para o conjunto de dados do Anexo 1 e outra para o conjunto de dados do Anexo 2. Na primeira análise, a tabela do Anexo 1 será tratada como uma matriz de dados com vinte e sete objetos (as vinte e sete UFs) e onze variáveis (as proporções das ocupações em cada uma das onze atividades econômicas). De forma análoga, na segunda análise, a tabela do Anexo 2 será tratada como uma matriz de dados com onze objetos (as onze atividades econômicas) e vinte e sete variáveis (as proporções das ocupações em cada uma das vinte e sete UFs).

Os primeiros resultados estão na Figura 3. Os grupos semelhantes apontados pela Análise de Grupamento são formados pelas Unidades que apresentam distribuições das ocupações nas atividades econômicas semelhantes ${ }^{4}$. O eixo horizontal é a distância entre os grupos. Quanto maior a distância, menor a semelhança entre os grupos e entre as UFs que os compõem. A primeira coluna a esquerda fornece o percentual do emprego na referida UF.

A leitura da Figura 3 permite identificar quatro grupos homogêneos. $\mathrm{O}$ primeiro grupo, (Sergipe,..., Rio Grande do Sul), formado por onze UFs, é o mais homogêneo. Observa-se que o grupo como um todo não apresenta característica regional, porém é possível perceber dois subgrupos, um com estados das regiões Norte, Nordeste e Centro-Oeste, outro com estados do Sul e Sudeste. De qualquer forma, a homogeneidade das onze UFs que compõem esse primeiro grupo é bastante alta se comparada com a máxima distância. O segundo grupo é formado por Acre, Roraima e Amapá, três estados da região Norte do país. O terceiro grupo, é formado por dez estados (Maranhão,..., Ceará), e, finalmente, o quarto grupo, bem diferente dos demais, é formado por Rio de Janeiro, São Paulo e Distrito Federal.

Observando-se os grupos formados e o nível de emprego no estado ( $1^{\mathrm{a}}$ coluna à esquerda), percebe-se que cada grupo formado contém Unidades com alta e baixa proporção da população ocupada. Isto é, os grupos não estão associados ao nível de emprego no estado nem às regiões geográficas. Para entender melhor as semelhanças e diferenças desses grupos, pode-se recorrer às médias das variáveis (média das proporções das ocupações em cada atividade econômica) dentro de cada grupo. Explicando melhor, tomando o primeiro grupo formado por (SE, ES, PA, RN, AM, MS, GO, MG, PR, SC, RS) observa-se que as proporções da ocupação na agricultura são, respectivamente: 0,$209 ; 0,212 ; 0,194 ; 0,231$; 0,$210 ; 0,185 ; 0,154 ; 0,197 ; 0,174 ; 0,184 ; 0,222$. Portanto, uma das características

(4) Os resultados das Análises de Grupamento apresentados nas Figuras 3 e 4 foram obtidos com auxílio do software SPSS - versão 16, pelo método Ward, com distância do $\chi 2$. 
desse grupo é que as proporções das ocupações na agricultura estão em torno de 0,20. Já o grupo 4 (RJ, SP, DF) apresentou as seguintes proporções na agricultura: 0,$021 ; 0,050 ; 0,012$, isto é, valores em torno de 0,03 . Esta é uma distinção forte entre esses dois grupos. Repetindo, com esse procedimento para os quatro grupos e para as onze atividades será possível caracterizar cada grupo por suas atividades mais importantes bem como entender suas semelhanças e diferenças. Esses resultados estão na Tabela 4. A última coluna à direita permite comparar a presença de cada atividade em cada grupo e a presença da mesma no Brasil.

Figura 3

Análise de grupamento para Unidades da Federação, segundo a distribuição da população ocupada

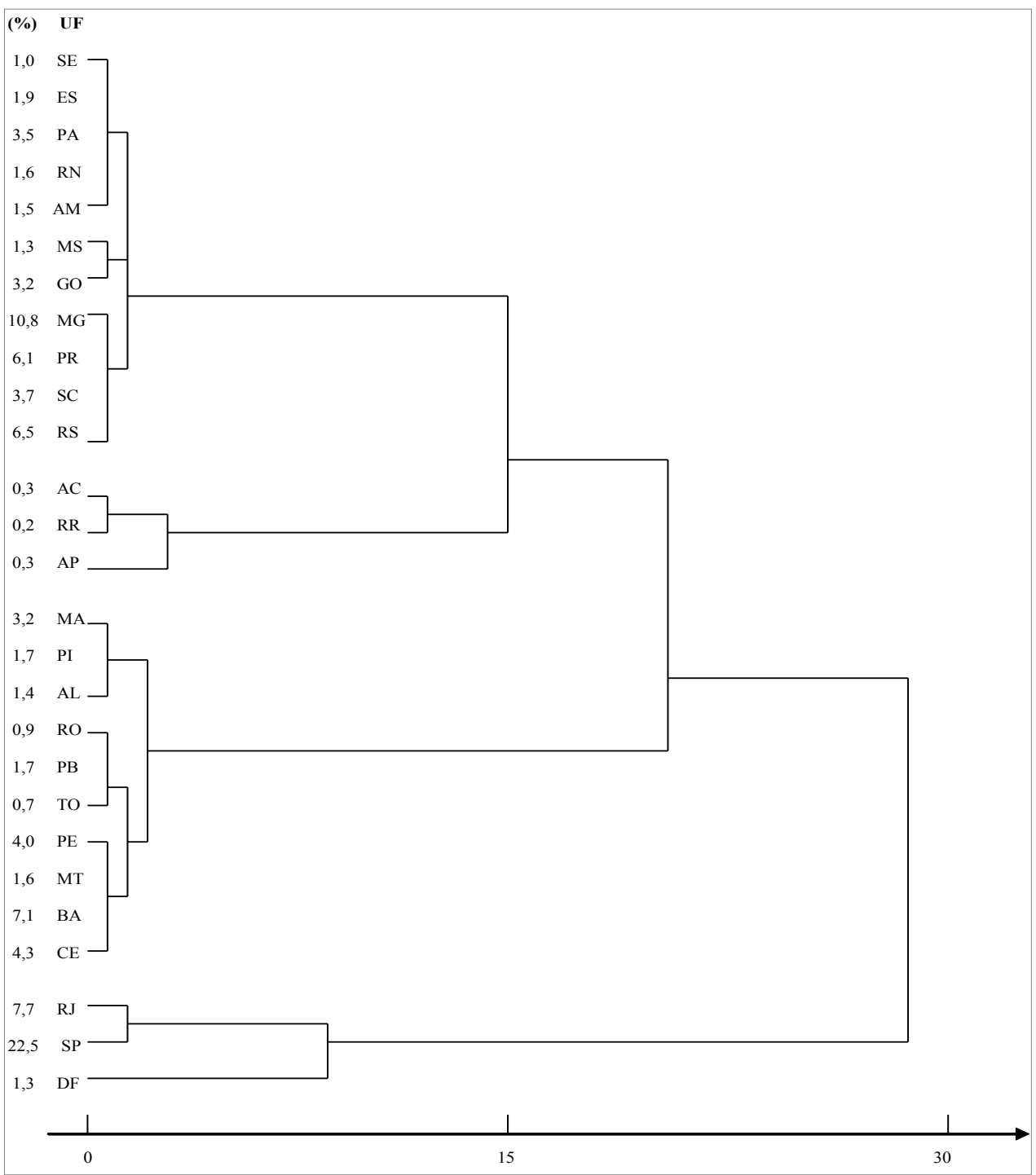


A população ocupada e a renda no Brasil: encontros e desencontros

Tabela 4

Média das variáveis dentro de cada grupo

\begin{tabular}{l|c|c|c|c|c}
\hline Atividades & Grupo1 & Grupo 2 & Grupo 3 & Grupo 4 & BR \\
\hline Agricultura, pecuária,... & $\mathbf{0 , 2 0}$ & $\mathbf{0 , 1 9}$ & $\mathbf{0 , 3 3}$ & 0,03 & 0,183 \\
\hline Indústria & $\mathbf{0 , 1 5}$ & 0,09 & $\mathbf{0 , 1 0}$ & $\mathbf{0 , 1 3}$ & 0,153 \\
\hline Construção civil & 0,07 & 0,07 & 0,06 & 0,07 & 0,067 \\
\hline Comércio e reparação & $\mathbf{0 , 1 8}$ & $\mathbf{0 , 1 8}$ & $\mathbf{0 , 1 6}$ & $\mathbf{0 , 1 9}$ & 0,180 \\
\hline Alojamento e alimentação & 0,04 & 0,03 & 0,03 & 0,05 & 0,037 \\
\hline Transporte,... & 0,05 & 0,04 & 0,03 & 0,06 & 0,048 \\
\hline Administração pública & 0,05 & $\mathbf{0 , 1 1}$ & 0,06 & 0,08 & 0,050 \\
\hline Educação,... & 0,09 & $\mathbf{0 , 1 2}$ & 0,08 & $\mathbf{0 , 1 2}$ & 0,093 \\
\hline Serviços domésticos & 0,07 & 0,07 & 0,07 & 0,09 & 0,074 \\
\hline Outros Serviços coletivos & 0,04 & 0,04 & 0,03 & 0,06 & 0,041 \\
\hline Intermediação Financeira... & 0,06 & 0,06 & 0,04 & $\mathbf{0 , 1 3}$ & 0,074 \\
\hline
\end{tabular}

(em negrito, proporção da ocupação igual a 0,10 ou mais)

Elaboração própria a partir dos dados da PNAD (2007).

A análise desta tabela permite afirmar que o grupo 1 está caracterizado por significativa participação na "Agricultura, pecuária, ...", na "Indústria" e "Comércio e reparação". Nota-se também a mais baixa participação da "Administração pública”. Já o grupo 2 (Acre, Roraima e Amapá), embora apresente participações semelhantes na "Agricultura, pecuária,..." e no "Comércio e reparação", diferencia-se do primeiro por sua baixa participação na "Indústria" e alta participação na "Administração pública" e "Educação,...". O grande destaque do grupo 3 é a "Agricultura, pecuária,...", embora "Indústria” e "Comércio e reparação" também estejam presentes neste grupo. De fato, a diferença deste para o grupo 1 ocorre pelo peso da "Agricultura, pecuária,..." muito maior no grupo 3 que em qualquer outro. Finalmente, o grupo 4, o mais distinto de todos, formado por Rio de Janeiro, São Paulo e Distrito Federal, é caracterizado, principalmente, pela ausência da "Agricultura, pecuária,..." e pela presença das atividades "Indústria”, "Comércio e reparação”, "Educação,..." e "Intermediação Financeira...”. É também o grupo no qual a proporção da população ocupada em "Serviços domésticos" é mais alta, focalizando, nessas Unidades, as mais ricas do país, a atividade com pior remuneração, dando, portanto, mais consistência à hipótese já levantada na análise do Quadro 2.

De modo geral, o que define os grupos é a maior ou menor participação na "Agricultura, pecuária,..." e na "Indústria" e a presença (ou ausência) nas atividades "Administração pública", "Educação,..." e "Intermediação Financeira...". Isto é, entre as onze atividades econômicas pesquisadas, essas cinco atividades apresentam proporções de ocupação diferenciadas entre as UFs, permitindo a identificação de grupos internamente semelhantes e distintos entre si. Ou ainda, essas são as atividades cujas diferenças regionais são mais acentuadas. 
A técnica de análise de grupamento foi também aplicada aos dados do Anexo 2, fornecendo grupos de atividades semelhantes no que se refere a suas distribuições de ocupação entre as UFs. Este resultado está na Figura 4. A primeira coluna, à esquerda, fornece o percentual do emprego na referida atividade.

Figura 4

Análise de grupamento das atividades econômicas, segundo a distribuição da população ocupada

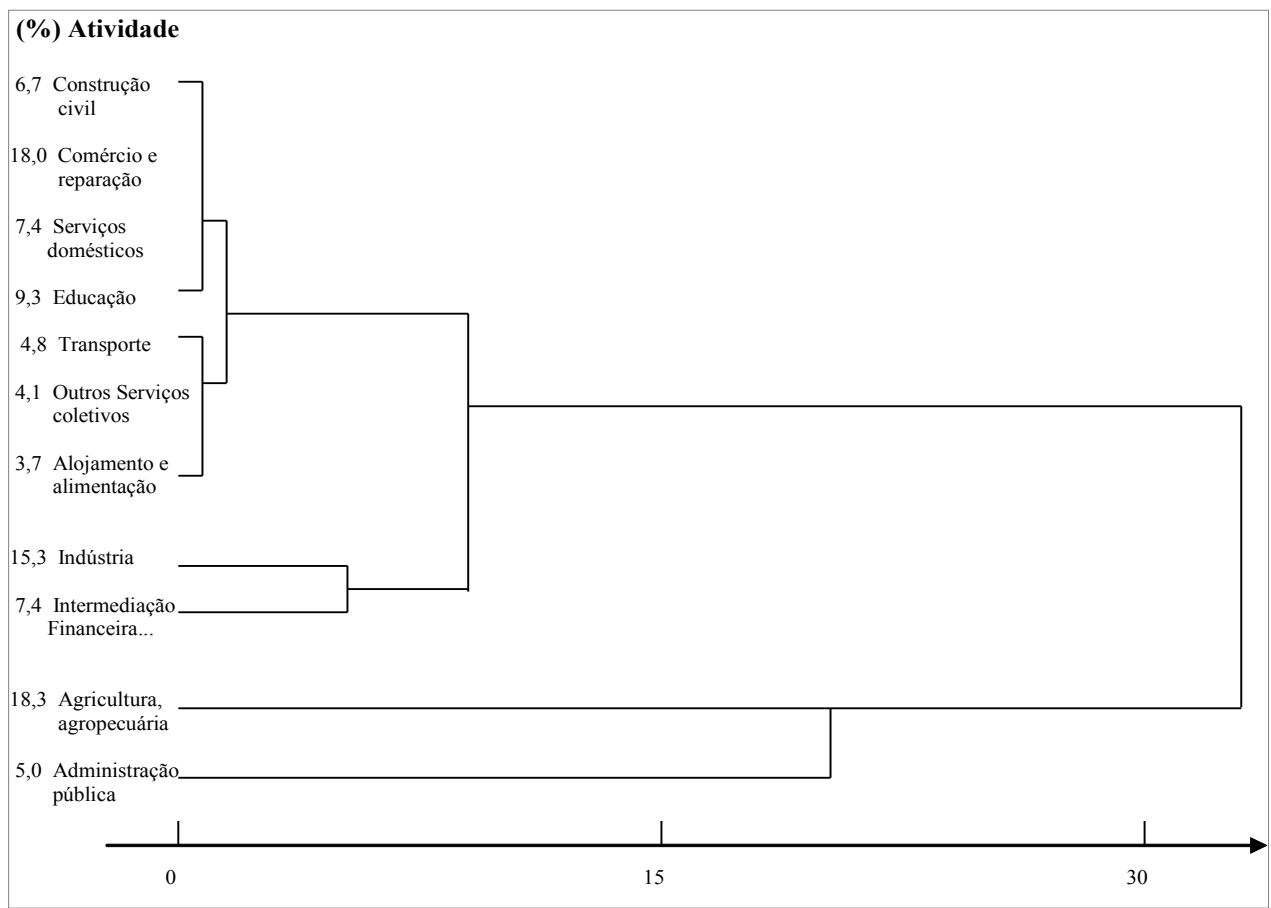

A leitura da Figura 4 fornece três grupos de atividades econômicas. $\mathrm{O}$ grupo 1, formado por sete atividades (Construção civil,... Alojamento e alimentação), é bastante homogêneo. Os grupos 2 e 3 (Indústria e Intermediações financeiras,...) e (Agropecuária e Administração pública), respectivamente, não são muito homogêneos (especialmente o grupo 3, muito pouco homogêneo). Nas análises anteriores (Quadro 2) foi possível concluir que essas atividades, presentes no grupo 2 e 3 , estão concentradas em certas regiões. Tomando o exemplo da "Agricultura", observa-se que $6,9 \%$ das ocupações nesta atividade estão no Maranhão, ao passo que esta UF contribui com apenas 3,2\% para a ocupação no país. Se analisarmos o Rio de Janeiro, onde a atividade agrícola não é muito presente, observamos que menos de $1 \%$ da "Agricultura" se encontra neste estado, que contribui com 7,7\% das ocupações do país. No caso das ocupações na "Indústria", 32\% estão em São Paulo, que contribui com 22,5\% da ocupação no país. Por outro lado, a contribuição do Distrito Federal na "Indústria" é de 0,4\%, enquanto, no total, a ocupação no Distrito Federal corresponde a 1,3\% do país. 
Assim, é interessante comparar as médias das variáveis dentro de cada grupo (média das proporções da ocupação, considerando apenas as atividades de cada grupo) com a proporção da população ocupada por UF. Se a diferença observada for significativa, há indicação de que as atividades do grupo estão concentradas em algumas UFs. Essas informações apresentam-se na Tabela 5.

Tabela 5

Média das variáveis dentro de cada grupo e a proporção da população ocupada por UF no Brasil

\begin{tabular}{|c|c|c|c|c|}
\hline UF & Grupo 1 & Grupo 2 & Grupo 3 & $\mathrm{BR}$ \\
\hline $\mathrm{RO}$ & 0,007 & 0,006 & $\mathbf{0 , 0 1 4}$ & 0,009 \\
\hline $\mathrm{AC}$ & 0,003 & 0,003 & 0,006 & 0,003 \\
\hline $\mathrm{AM}$ & 0,015 & 0,013 & 0,017 & 0,015 \\
\hline $\mathrm{RR}$ & 0,002 & 0,002 & 0,005 & 0,002 \\
\hline PA & 0,035 & 0,027 & 0,039 & 0,035 \\
\hline AP & 0,004 & 0,002 & 0,003 & 0,003 \\
\hline TO & 0,007 & 0,004 & 0,012 & 0,007 \\
\hline MA & 0,025 & 0,014 & 0,048 & 0,032 \\
\hline PI & 0,013 & 0,007 & 0,028 & 0,017 \\
\hline $\mathrm{CE}$ & 0,036 & 0,035 & 0,049 & 0,043 \\
\hline $\mathrm{RN}$ & 0,015 & 0,012 & 0,019 & 0,016 \\
\hline PB & 0,016 & 0,011 & 0,025 & 0,017 \\
\hline PE & 0,037 & 0,030 & 0,051 & 0,04 \\
\hline $\mathrm{AL}$ & 0,011 & 0,008 & 0,025 & 0,014 \\
\hline SE & 0,010 & 0,009 & 0,013 & 0,01 \\
\hline BA & 0,064 & 0,042 & 0,102 & 0,071 \\
\hline MG & 0,109 & 0,100 & 0,107 & 0,108 \\
\hline ES & 0,018 & 0,017 & 0,023 & 0,019 \\
\hline RJ & 0,103 & 0,089 & 0,053 & 0,077 \\
\hline SP & 0,243 & $\mathbf{0 , 3 3 2}$ & 0,120 & 0,225 \\
\hline PR & 0,061 & 0,063 & 0,055 & 0,061 \\
\hline $\mathrm{SC}$ & 0,032 & 0,043 & 0,036 & 0,037 \\
\hline $\mathrm{RS}$ & 0,056 & 0,071 & 0,068 & 0,065 \\
\hline MS & 0,014 & 0,010 & 0,016 & 0,013 \\
\hline MT & 0,014 & 0,012 & 0,021 & 0,016 \\
\hline GO & 0,035 & 0,029 & 0,033 & 0,032 \\
\hline DF & 0,015 & 0,017 & 0,019 & 0,013 \\
\hline
\end{tabular}

Negrito onde as proporções são acentuadamente maiores da proporção no Brasil.

Observa-se que o grupo 1 (Construção, Comércio, Serviços domésticos, Educação, Transportes, Outros serviços coletivos e Alojamento), apontado na Figura 4 como o mais homogêneo, é também aquele cujas proporções raramente diferem acentuadamente das proporções de cada UF no Brasil, indicando que, em 
geral, não há concentração dessas atividades nas Unidades da Federação. O grupo 2 (Indústria e Intermediação financeira...) apresenta valores bem maiores que a proporção para o Brasil (última coluna à direita) para RJ, SP, SC e DF, indicando que são nesses estados que as duas atividades estão concentradas. Já o grupo 3 (Agricultura e Administração pública) apresenta destaques para as regiões do Norte e Nordeste e também para ES, MS, MT e DF. Nota-se que este é o grupo menos homogêneo, e as análises anteriores dos Quadros 1 e 2 permitem afirmar que alguns desses estados se destacam pela presença da Agricultura, enquanto outros pela presença da Administração pública.

Como principal resultado destas observações, pode-se dizer que a análise de grupamento separou as atividades que não apresentam concentração regional (grupo 1) daquelas que apresentam concentração em alguns estados (grupos 2 e 3).

\section{O ponto de vista da renda mensal média}

A segunda parte da análise das Atividades Econômicas e das Unidades da Federação focaliza a renda mensal média. Como visto no início deste trabalho, há fortes diferenças na remuneração tanto nas Atividades Econômicas como nas regiões. Ao analisarmos conjuntamente Atividades Econômicas e Unidades da Federação, os efeitos são combinados de tal maneira que "boas atividades" se apresentam como muito melhores no Sul e Sudeste e "más atividades" se revelam ainda piores no Norte e no Nordeste. Ao focalizarmos determinada UF, as desigualdades nas remunerações de acordo com as atividades estão presentes. Da mesma forma, tomando-se uma determinada atividade, verificam-se marcantes desigualdades regionais. A desigualdade nos rendimentos é o que há de comum em qualquer UF ou Atividade Econômica.

O Anexo 3 apresenta tabela contendo a renda mensal média, em salários mínimos, por Unidade da Federação e por Atividade Econômica. A última linha fornece a renda mensal média na atividade econômica no Brasil, e a última coluna fornece a renda mensal média na UF.

Observa-se que, das 27 UFs, apenas sete têm renda média acima da média brasileira (Rio de Janeiro, São Paulo, Paraná, Santa Catarina, Rio Grande do Sul, Mato Grosso do Sul, Distrito Federal). Por outro lado, as atividades que correspondem a renda maior que a média nacional são cinco: "Indústria", "Transportes...", "Administração pública”, "Educação, saúde, ...”, "Intermediações financeiras...". Outro fato que merece destaque é que entre as onze atividades econômicas, a "Administração pública" apresenta a maior renda em 26 das 27 Unidades da Federação. A única exceção ocorre no Mato Grosso, 
onde essa atividade representa o segundo maior valor (3,35 s.m.), perdendo apenas para "Intermediações financeiras,..." (3,61 s.m.). Além dessas informações gerais, os dados do Anexo 3 permitem duas leituras, uma pelas linhas, examinando as Unidades da Federação, outra pelas colunas, examinando as atividades econômicas. Os Quadros 4 e 5 mostram esses dois pontos de vista.

Quadro 4

Unidades da Federação que pagam mais que a média nacional em cada atividade

\begin{tabular}{|c|c|c|c|c|c|c|c|c|c|c|c|}
\hline UF & 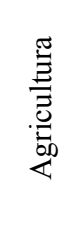 & 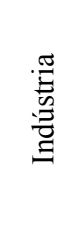 & 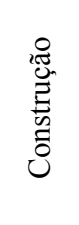 & 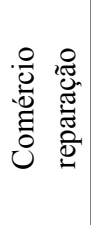 & 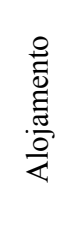 & 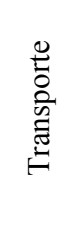 & 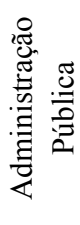 & 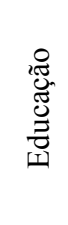 & 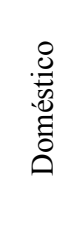 & 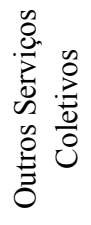 & 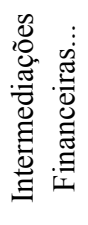 \\
\hline RO & & & & & & & & & & & \\
\hline $\mathrm{AC}$ & & & & & & & 4,49 & & & & \\
\hline AM & & & & & & & & & & & \\
\hline $\mathrm{RR}$ & & & & & & & & & & & \\
\hline PA & & & & & & & & & & & \\
\hline AP & & & & & & & 4,38 & 3,31 & & & \\
\hline TO & & & & & & & & & & & \\
\hline MA & & & & & & & & & & & \\
\hline PI & & & & & & & & & & & \\
\hline $\mathrm{CE}$ & & & & & & & & & & & \\
\hline RN & & & & & & & & & & & \\
\hline PB & & & & & & & & & & & \\
\hline PE & & & & & & & & & & & \\
\hline $\mathrm{AL}$ & & & & & & & & & & & \\
\hline SE & & & & & & & & & & & \\
\hline BA & & & & & & & & & & & \\
\hline MG & & & & & & & & & & & \\
\hline ES & 1,78 & & 2,23 & & & & & & & & \\
\hline RJ & & 2,89 & 2,29 & & 2,18 & 3,23 & 4,50 & 3,19 & 1,20 & 2,50 & \\
\hline SP & 2,11 & 3,12 & 2,59 & 2,96 & 2,35 & 3,64 & 4,12 & 3,50 & 1,22 & 2,81 & \\
\hline PR & 2,45 & & 2,26 & 2,50 & 2,18 & 3,43 & & & 0,98 & 2,55 & \\
\hline $\mathrm{SC}$ & 2,22 & 2,71 & 3,02 & 2,97 & 2,42 & 3,47 & 4,23 & 3,55 & 1,19 & 2,46 & \\
\hline $\mathrm{RS}$ & 2,12 & & & 2,57 & 2,16 & 3,30 & & 3,15 & 1,01 & 2,44 & \\
\hline MS & 2,19 & & & & & & 4,10 & 3,31 & & & \\
\hline MT & 2,12 & & 2,26 & 2,58 & 2,12 & 3,24 & & & & & \\
\hline GO & 2,02 & & & & 2,12 & & & & & & \\
\hline DF & 2,57 & 3,19 & 2,51 & 2,96 & 2,54 & 3,87 & 7,36 & 5,40 & 1,23 & 3,18 & 4,35 \\
\hline $\mathrm{BR}$ & 1,74 & 2,65 & 2,14 & 2,49 & 2,03 & 3,21 & 4,09 & 3,13 & 0,91 & 2,31 & 3,82 \\
\hline
\end{tabular}

Na quase total ausência das regiões Norte e Nordeste, chama atenção a presença do Acre, apresentando renda maior que a média na "Administração 
pública", e Amapá, com renda maior que a média para "Administração pública" e "Educação". Voltando aos dados do Anexo 1, vê-se que essas atividades são importantes para essas UFs no que se refere a proporção da população ocupada. Esse resultado reforça a importância dessas duas atividades nessas UFs, pois são atividades em que ocorre concentração de ocupações e renda superior a média nacional. A Região Sudeste apresenta um resultado oposto, com quase todas as UFs apresentando valores acima da média. Destaca-se a ausência de Minas Gerais, especialmente levando em conta que neste estado estão concentrados mais que $10 \%$ da população ocupada do Brasil. A Região Sul está bem representada, sendo que Santa Catarina apresenta renda maior que a média nacional em dez das onze atividades. O destaque positivo da Região Centro-Oeste (excluindo-se, neste momento, o Distrito Federal, por suas características muito diferentes das demais UFs dessa região) está no Mato Grosso, com cinco atividades apresentando renda maior que a média no Brasil, muito embora as atividades presentes para essa UF não sejam as que melhor remuneram. As melhores Unidades da Federação são Distrito Federal, São Paulo e Santa Catarina, que apresentam, respectivamente, onze, dez e dez atividades com renda maior que a média brasileira.

A seguir passaremos à análise das atividades econômicas presente nas Unidades da Federação no que se refere aos rendimentos médios. O Quadro 5 mostra as atividades que remuneram mais que a média de cada Unidade da Federação.

Nesse momento, é interessante lembrar um dos primeiros resultados desse artigo, que indicava uma concentração de ocupações nas atividades "Agricultura, pecuária,...", "Indústria” e "Comércio e reparação" (51\% das ocupações). Ao focalizar a renda mensal média em cada atividade econômica, verifica-se que estas atividades, na maioria dos casos, remuneram abaixo da média observada na Unidade da Federação. A melhor das três é a atividade de "Comércio $e$ reparação" que apresenta rendimento maior que a média em sete das vinte e sete Unidades da Federação. A "Indústria” apresenta rendimento maior que a média em cinco estados, e "Agricultura, pecuária,.." não apresenta rendimento maior que a média observada para a Unidade da Federação em nenhum caso. Outras atividades totalmente ausentes no Quadro 5 são "Alojamento..." e "Serviços domésticos". No outro extremo, as melhores atividades, que quase sempre remuneram melhor que a média, são "Administração Pública”, "Educação..." e "Intermediações financeiras...". Essas três atividades econômicas correspondem a 21,7\% da ocupação no Brasil. A atividade de "Transportes..." também pode ser considerada uma atividade que remunera bem, já que remunera mais que a média em vinte e quatro das vinte e sete Unidades da Federação. 
A população ocupada e a renda no Brasil: encontros e desencontros

Quadro 5

Atividades que pagam mais que a média em cada UF

\begin{tabular}{|c|c|c|c|c|c|c|c|c|c|c|c|c|}
\hline UF & 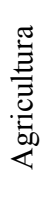 & 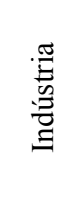 & 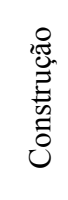 & 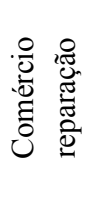 & 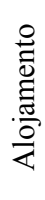 & 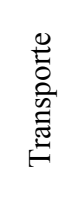 & 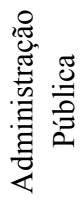 & 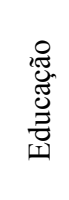 & 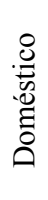 & 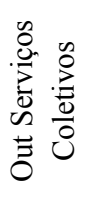 & 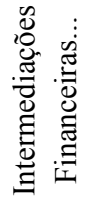 & 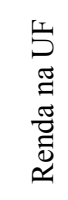 \\
\hline RO & & & & 2,20 & & 2,76 & 3,84 & 3,03 & & & 3,35 & 2,19 \\
\hline $\mathrm{AC}$ & & & & & & 2,93 & 4,49 & 3,11 & & & 2,72 & 2,42 \\
\hline AM & & & & 2,33 & & 2,62 & 3,54 & 2,51 & & & 3,05 & 2,23 \\
\hline RR & & & & & & 2,46 & 3,50 & 2,87 & & & 2,36 & 1,99 \\
\hline PA & & 1,96 & & & & 2,47 & 2,91 & 2,35 & & & 2,89 & 1,91 \\
\hline AP & & & & & & & 4,38 & 3,31 & & & 2,66 & 2,38 \\
\hline TO & & & & 2,10 & & & 3,11 & 2,23 & & & 3,06 & 2,02 \\
\hline MA & & 1,62 & 1,57 & 1,77 & & 1,86 & 2,53 & 1,74 & & & 2,16 & 1,53 \\
\hline PI & & & & & & 1,68 & 2,96 & 2,05 & & & 2,69 & 1,44 \\
\hline $\mathrm{CE}$ & & & & 1,61 & & 2,27 & 2,95 & 1,95 & & 1,51 & 2,38 & 1,46 \\
\hline RN & & & & & & 1,89 & 3,05 & 2,22 & & & 2,21 & 1,82 \\
\hline PB & & & & & & 1,79 & 2,93 & 2,16 & & & 2,78 & 1,72 \\
\hline PE & & 1,67 & & 1,64 & & 1,85 & 2,83 & 2,02 & & & 2,42 & 1,63 \\
\hline AL & & & & & & 2,24 & 2,86 & 1,91 & & & 2,69 & 1,76 \\
\hline SE & & & & & & 2,23 & 3,31 & 2,10 & & & 2,35 & 1,76 \\
\hline BA & & 1,82 & & & & 2,04 & 2,62 & 2,20 & & & 2,62 & 1,60 \\
\hline MG & & 2,26 & & & & 2,97 & 3,20 & 2,65 & & & 3,02 & 2,23 \\
\hline ES & & & & & & 3,02 & 3,10 & 2,54 & & & 3,10 & 2,45 \\
\hline RJ & & & & & & 3,23 & 4,50 & 3,19 & & & 3,65 & 2,99 \\
\hline SP & & & & & & 3,64 & 4,12 & 3,50 & & & 3,82 & 3,20 \\
\hline PR & & & & & & 3,43 & 3,78 & 3,09 & & & 3,76 & 2,86 \\
\hline $\mathrm{SC}$ & & & 3,02 & & & 3,47 & 4,23 & 3,55 & & & 3,75 & 2,97 \\
\hline $\mathrm{RS}$ & & & & & & 3,30 & 3,72 & 3,15 & & & 3,56 & 2,65 \\
\hline MS & & & & & & 3,04 & 4,10 & 3,31 & & & 3,42 & 2,71 \\
\hline MT & & & & 2,58 & & 3,24 & 3,35 & 3,01 & & & 3,61 & 2,46 \\
\hline GO & & & & & & 2,87 & 3,57 & 2,90 & & & 2,95 & 2,49 \\
\hline DF & & & & & & & 7,36 & 5,40 & & & & 5,19 \\
\hline
\end{tabular}

Procurando mais uma vez a associação entre UFs e atividades econômicas, o Quadro 6, abaixo, apresenta a interseção dos Quadros 4 e 5. Os pontos assinalados correspondem à situação na qual há simultaneamente renda maior que a média na atividade e renda maior que a média na UF.

Estão presentes quatro atividades econômicas, "Construção", "Transporte...", "Administração pública", "Educação..." e dez Unidades da Federação, duas do Norte (Acre e Amapá), duas do Sudeste (Rio de Janeiro e São Paulo), três do Sul (Paraná, Santa Catarina e Rio Grande do Sul) e três do CentroOeste (Mato Grosso do Sul, Mato Grosso e Distrito Federal). Todos os estados da 
Região Nordeste estão ausentes. Como já observado anteriormente, as maiores rendas correspondem à "Administração pública" com valores surpreendentes no Acre (4,49 s.m.) e Amapá (4,38 s.m.).

Quadro 6

Interseção dos Quadros 4 e 5

\begin{tabular}{|c|c|c|c|c|c|c|c|c|c|c|c|c|}
\hline UF & 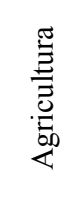 & 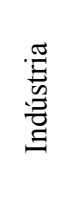 & 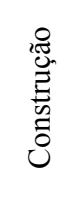 & 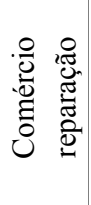 & $\begin{array}{l}\frac{0}{0} \\
\frac{0}{0} \\
\frac{\pi}{0} \\
\frac{0}{2}\end{array}$ & 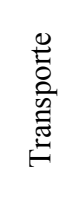 & 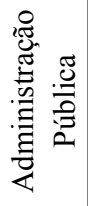 & 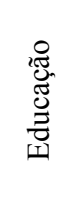 & 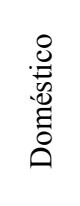 & 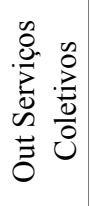 & 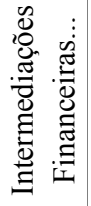 & 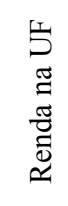 \\
\hline $\mathrm{RO}$ & & & & & & & & & & & & 2,19 \\
\hline $\mathrm{AC}$ & & & & & & & 4,49 & & & & & 2,42 \\
\hline $\mathrm{AM}$ & & & & & & & & & & & & 2,23 \\
\hline RR & & & & & & & & & & & & 1,99 \\
\hline PA & & & & & & & & & & & & 1,91 \\
\hline AP & & & & & & & 4,38 & 3,31 & & & & 2,38 \\
\hline TO & & & & & & & & & & & & 2,02 \\
\hline MA & & & & & & & & & & & & 1,53 \\
\hline PI & & & & & & & & & & & & 1,44 \\
\hline $\mathrm{CE}$ & & & & & & & & & & & & 1,46 \\
\hline $\mathrm{RN}$ & & & & & & & & & & & & 1,82 \\
\hline PB & & & & & & & & & & & & 1,72 \\
\hline PE & & & & & & & & & & & & 1,63 \\
\hline AL & & & & & & & & & & & & 1,76 \\
\hline SE & & & & & & & & & & & & 1,76 \\
\hline BA & & & & & & & & & & & & 1,60 \\
\hline MG & & & & & & & & & & & & 2,23 \\
\hline ES & & & & & & & & & & & & 2,45 \\
\hline RJ & & & & & & 3,23 & 4,50 & 3,19 & & & & 2,99 \\
\hline SP & & & & & & 3,64 & 4,12 & 3,50 & & & & 3,20 \\
\hline PR & & & & & & 3,43 & & & & & & 2,86 \\
\hline $\mathrm{SC}$ & & & 3,02 & & & 3,47 & 4,23 & 3,55 & & & & 2,97 \\
\hline $\mathrm{RS}$ & & & & & & 3,30 & & 3,15 & & & & 2,65 \\
\hline MS & & & & & & & 4,10 & 3,31 & & & & 2,71 \\
\hline MT & & & & & & 3,24 & & & & & & 2,46 \\
\hline GO & & & & & & & & & & & & 2,49 \\
\hline DF & & & & & & & 7,36 & 5,40 & & & & 5,19 \\
\hline BR & 1,74 & 2,65 & 2,14 & 2,49 & 2,03 & 3,21 & 4,09 & 3,13 & 0,91 & 2,31 & 3,82 & 2,48 \\
\hline
\end{tabular}

A partir dos dados do Anexo 3, foram realizadas duas Análises de Grupamento: a primeira, agregando Unidades da Federação semelhantes (linhas da tabela) no que se refere às rendas médias nas atividades e outra, agregando atividades econômicas semelhantes (colunas da tabela) no que se refere às rendas médias nas UFs. O primeiro resultado pode ser observado na Figura 5. A primeira 
coluna à esquerda informa a renda média mensal nas respectivas Unidades da Federação.

Figura 5

Análise de grupamento das Unidades da Federação - Rendimentos médios

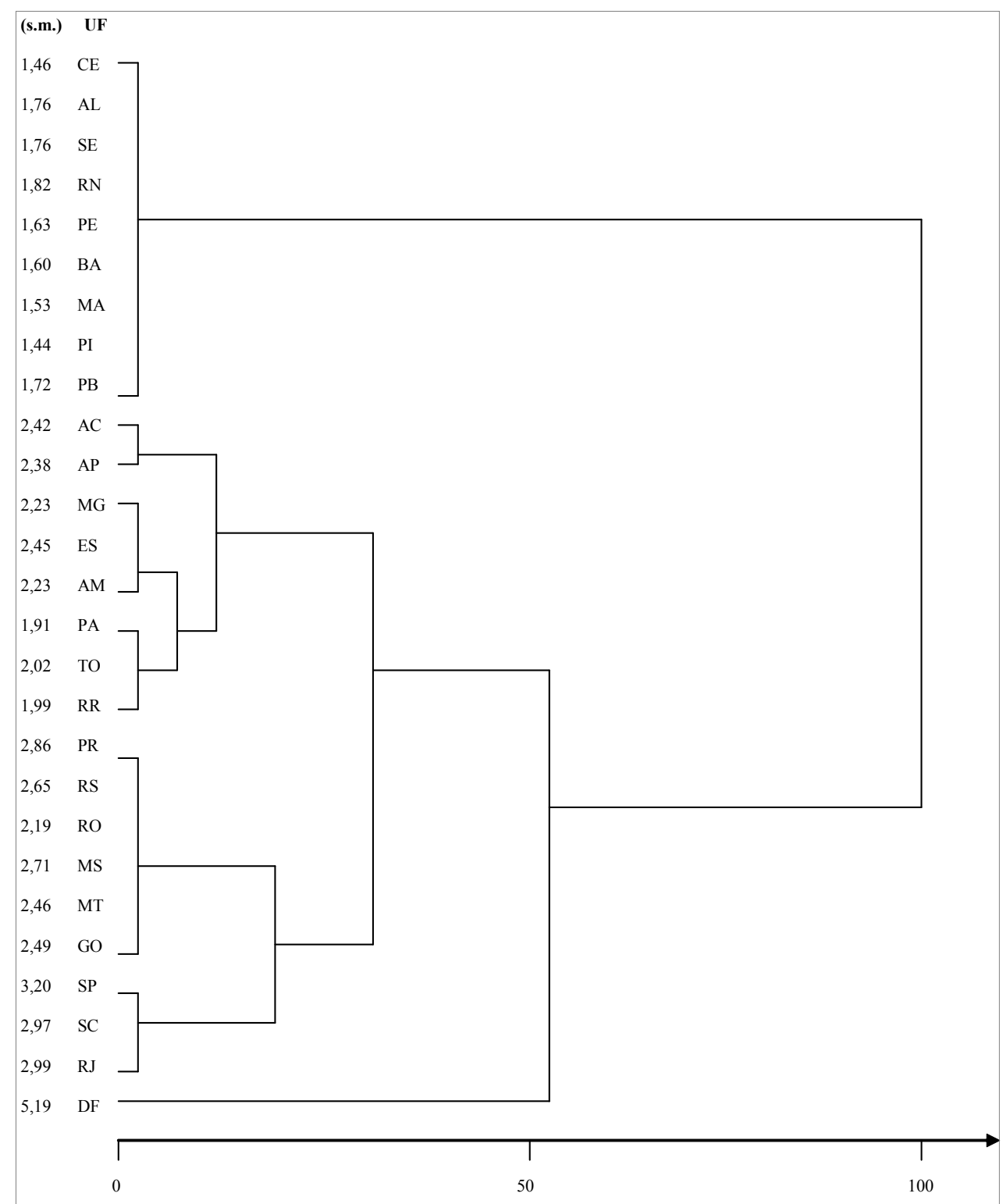

Observa-se que os grupos formados correspondem a diferentes níveis de renda. O primeiro grupo (Ceará,... Paraíba) reúne estados com renda média abaixo de dois salários mínimos. São os nove estados do Nordeste. O segundo grupo 
(Acre,... Roraima) inclui estados com renda média em torno de dois salários mínimos. Neste grupo estão os estados do Norte (exceto Rondônia) e dois do Sudeste: Minas Gerais e Espírito Santo. O terceiro (Paraná,... Rio de Janeiro) inclui os estados com maior renda média, localizados no Sul, Sudeste e CentroOeste. Isolado de todos os grupos está o Distrito federal, cuja renda média é a maior entre as Unidades da Federação do Brasil (5,19 s.m.). Os grupos formados são facilmente explicados pelo nível de renda das UFs, ao contrário da análise da população ocupada (Figura 3), na qual o nível de participação em algumas atividades é que define os grupos, e não o nível de emprego das UFs. O significado deste grupamento por nível de renda média consiste em que, apesar das atividades apresentarem remunerações diferenciadas nas UFs, o que predomina é o nível de renda de cada uma. Pode-se dizer que a informação adicional dos diferentes rendimentos nas atividades dentro de cada UF não alterou a estrutura de grupos das UFs, tendo como critério a renda média.

A análise de grupamento das atividades econômicas, considerando a renda mensal média, forneceu o resultado apresentado na Figura 6.

Figura 6

Análise de grupamento das Atividades Econômicas - Rendimentos médios

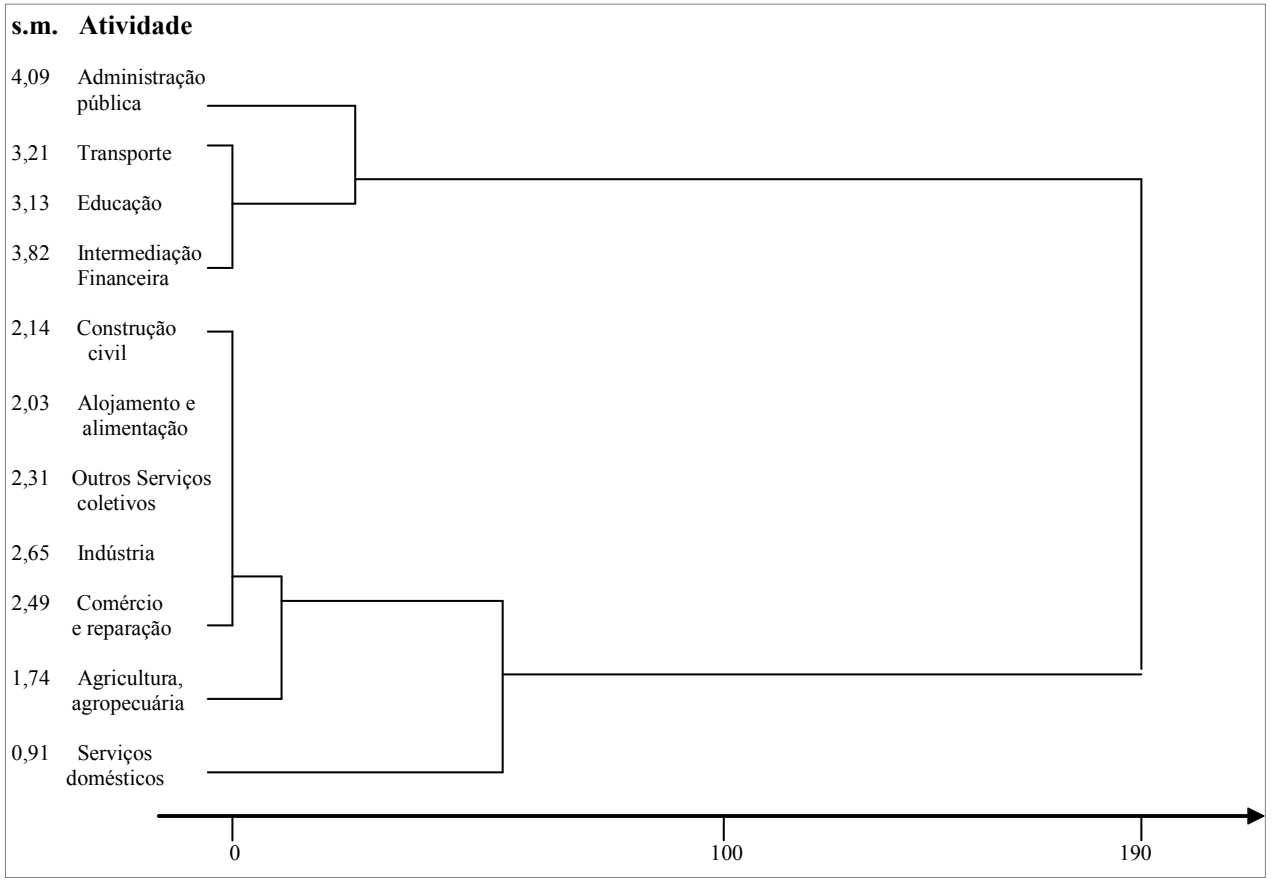

Percebem-se dois grupos de atividades, o primeiro composto por aquelas com maior remuneração, isto é, as que pagam mais que a média na UF: "Administração pública", "Transporte...", "Educação..." e "Intermediações 
financeiras....". O segundo grupo, que corresponde às atividades que remuneram abaixo da média da UF: "Construção civil", "Alojamento e alimentação", "Outros serviços coletivos", "Indústria”, "Comércio e reparação”, "Agricultura pecuária...". Um pouco isolada das demais encontra-se "Serviços domésticos", atividade que apresenta a menor renda mensal média. Nesta solução de análise de grupamento, a estrutura de grupos corresponde também aos níveis de rendimento nas atividades. Isto é, separa as atividades com altos rendimentos daquelas com baixo rendimento.

\section{Encontros e desencontros: onde ocorrem?}

Em vários trechos deste trabalho, foram apontados encontros $\mathrm{e}$ desencontros entre a população ocupada e a renda. Aprofundando um pouco essa questão, serão examinados os dados dos Anexos 1 e 3. As informações ali apresentadas possibilitarão focalizar onde (em que atividades e em quais estados) há encontros e onde há desencontros. Para isso, foram considerados, em cada localidade, os três maiores valores de renda e os três maiores valores da proporção da ocupação. Por exemplo, pensando no Brasil de forma agregada, as maiores proporções da ocupação estão na "Agricultura,...", "Comércio e reparação" e "Indústria". Os maiores valores de renda estão na "Administração pública", “Intermediações financeiras...” e "Transportes...”. Não há encontro.

Se analisarmos cada Unidade da Federação, veremos que, em alguns casos, há encontro. Na verdade este encontro ocorre em sete das vinte e sete Unidades, nas atividades "Administração pública", "Educação..." $\mathrm{e}$ "Intermediações financeiras...". O Quadro 7 apresenta as três atividades com maiores proporções da ocupação (\%), e as três atividades com maiores rendas (\$) nas vinte e sete Unidades da Federação.

Focalizando os encontros da população ocupada e da renda, observa-se que, em Roraima, o maior valor da renda ocorre na "Administração pública", onde se percebe também a terceira maior proporção da ocupação. No Amapá, os encontros se dão na "Administração pública" e na "Educação". Em Tocantins e Piauí, a atividade de "Educação..." corresponde ao terceiro valor de renda e ao terceiro valor na ocupação. Na Bahia, o encontro se dá, mais uma vez, na atividade de "Educação...", que corresponde ao segundo valor de renda e ao terceiro valor na ocupação. Em São Paulo, "Intermediações financeiras...” corresponde ao terceiro valor na ocupação e ao segundo valor da renda. Finalmente no Distrito Federal, o encontro ocorre nas atividades de "Administração pública" e "Intermediações financeiras...". Interessante observar que, das sete Unidades onde há algum encontro, cinco são do Norte e Nordeste, as duas regiões mais pobres do país. 
Quadro 7

Assinalando os encontros da renda (\$) e da ocupação (\%)

\begin{tabular}{|c|c|c|c|c|c|c|c|c|c|c|c|}
\hline UF & 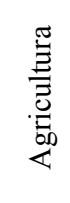 & 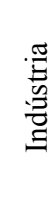 & 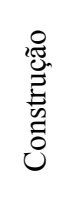 & 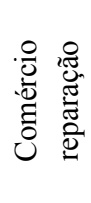 & 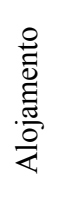 & 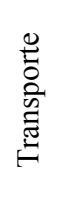 & 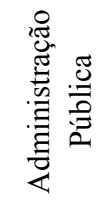 & 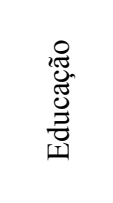 & 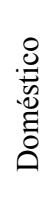 & 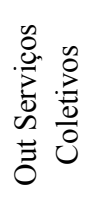 & 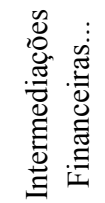 \\
\hline RO & $(\%)$ & $(\%)$ & & (\%) & & & (\$) & (\$) & & & (\$) \\
\hline $\mathrm{AC}$ & $(\%)$ & (\%) & & (\%) & & (\$) & (\$) & (\$) & & & \\
\hline AM & $(\%)$ & $(\%)$ & & (\%) & & (\$) & (\$) & & & & (\$) \\
\hline RR & $(\%)$ & & & (\%) & & (\$) & $(\$)(\%)$ & (\$) & & & \\
\hline PA & $(\%)$ & (\%) & & (\%) & & (\$) & $(\$)$ & & & & (\$) \\
\hline AP & & & (\%) & (\%) & & & $(\%)(\$)$ & $(\%)(\$)$ & & & (\$) \\
\hline TO & (\%) & & (\%) & & & & $(\$)$ & $(\%)(\$)$ & & & (\$) \\
\hline MA & (\%) & & & (\%) & & (\$) & (\$) & $(\%)$ & & & (\$) \\
\hline PI & $(\%)$ & & & $(\%)$ & & & (\$) & $(\%)(\$)$ & & & (\$) \\
\hline $\mathrm{CE}$ & (\%) & (\%) & & (\%) & & (\$) & (\$) & & & & (\$) \\
\hline RN & $(\%)$ & (\%) & & (\%) & & & (\$) & (\$) & & & (\$) \\
\hline PB & $(\%)$ & (\%) & & (\%) & & & (\$) & (\$) & & & (\$) \\
\hline $\mathrm{PE}$ & (\%) & (\%) & & (\%) & & & (\$) & (\$) & & & (\$) \\
\hline $\mathrm{AL}$ & (\%) & (\%) & & (\%) & & (\$) & (\$) & & & & (\$) \\
\hline SE & $(\%)$ & (\%) & & (\%) & & (\$) & (\$) & & & & (\$) \\
\hline BA & (\%) & (\%) & & (\%) & & (\$) & (\$) & $(\%)(\$)$ & & & (\$) \\
\hline MG & (\%) & (\%) & & (\%) & & (\$) & $(\$)$ & & & & (\$) \\
\hline ES & $(\%)$ & (\%) & & $(\%)$ & & (\$) & (\$) & (\$) & & & (\$) \\
\hline RJ & & (\%) & & (\%) & & (\$) & (\$) & (\%) & & & (\$) \\
\hline SP & & (\%) & & (\%) & & (\$) & (\$) & & & & $(\%)(\$)$ \\
\hline PR & (\%) & (\%) & & (\%) & & (\$) & (\$) & & & & $(\$)$ \\
\hline $\mathrm{SC}$ & (\%) & (\%) & & (\%) & & & $(\$)$ & (\$) & & & $(\$)$ \\
\hline RS & (\%) & (\%) & & (\%) & & (\$) & (\$) & & & & (\$) \\
\hline MS & (\%) & (\%) & & (\%) & & & (\$) & (\$) & & & (\$) \\
\hline MT & (\%) & (\%) & & $(\%)$ & & (\$) & (\$) & & & & (\$) \\
\hline GO & $(\%)$ & $(\%)$ & & $(\%)$ & & & $(\$)$ & (\$) & & & $(\$)$ \\
\hline DF & & & & (\%) & & & $(\%)(\$)$ & (\$) & & & $(\%)(\$)$ \\
\hline BR & $(\%)$ & $(\%)$ & & $(\%)$ & & (\$) & $(\$)$ & & & & (\$) \\
\hline
\end{tabular}

Estados com bons desempenhos econômicos como os das regiões Sul e Sudeste, com exceção de São Paulo, não apresentam encontros entre a população ocupada e renda, se separamos as ocupações pelas atividades econômicas, o que reforça nossa hipótese de que as desigualdades se repetem em diferentes escalas salariais, nas diferentes regiões do país. De acordo com o observado diversas vezes neste trabalho, é razoável supor que o indivíduo que sai do Nordeste para o Sudeste foge da pobreza para cair em outra pobreza. Não há dúvida que há forte ganho para o indivíduo mas, comparativamente, em seu novo domicílio, continua tão pobre como antes, ou se torna ainda mais pobre. 


\section{Conclusões}

Neste trabalho são percorridos quatro caminhos para analisar o mercado de trabalho brasileiro: as ocupações nas Unidades da Federação, as ocupações nas atividades econômicas, os rendimentos nas Unidades e o rendimento nas atividades. As três principais atividades econômicas, no que se refere à participação das ocupações, são "Agricultura, pecuária,...", "Indústria” e "Comércio e reparação", correspondendo a 51\% das ocupações no país. Pela via da renda mensal média, as atividades mais importantes são: "Administração pública", "Intermediação financeira,..." e "Transportes...", com rendimento mensal médio entre 1220 e 1554 reais. Focalizando as cinco Unidades com maior participação no mercado de trabalho temos São Paulo, Minas Gerais, Rio de Janeiro, Bahia e Rio Grande do Sul (54,6\% das ocupações). Por outro lado, aquelas que apresentam maior remuneração são Distrito Federal, São Paulo, Rio de Janeiro, Santa Catarina, Paraná (rendimentos entre 1087 e 1971 reais).

O cruzamento das atividades e Unidades da Federação permitiu formar dois panoramas distintos, um, retratando as ocupações, outro, os rendimentos mensais médios. Sob o ponto de vista das ocupações, foi possível estabelecer uma associação entre cinco atividades econômicas e doze Unidades da Federação (Quadro 3). Foram apontadas as situações nas quais as atividades econômicas e Unidades da Federação são mutuamente importantes, como por exemplo, nos estados do Ceará, Minas Gerais, Paraná, Santa Catarina e Rio Grande do Sul nas atividades de "Agricultura,...", "Indústria”, "Comércio e reparação”. A análise, sob o ponto de vista da renda, permitiu também destacar pares (estados e atividades) nos quais a renda mensal média apresenta-se acima da média tanto na Unidade da Federação como na atividade econômica (Quadro 6). Destacam-se, principalmente, Rio de Janeiro, São Paulo e Santa Catarina nas atividades de "Transportes...", "Administração pública" e "Educação...".

A análise das semelhanças e diferenças mostrou que as atividades econômicas que são semelhantes quanto à distribuição das ocupações não são semelhantes quanto aos rendimentos. Esse descompasso ocorre também na análise das Unidades da Federação, isto é, os grupos formados nas análises para ocupação (Figuras 3 e 4) não são os mesmos que os formados nas análises para renda (Figuras 5 e 6). Quando o critério é dado pelas ocupações, as Unidades da Federação são grupadas, principalmente, segundo a maior ou menor participação na agropecuária e na indústria, enquanto as atividades econômicas são grupadas de tal forma que é possível identificar aquelas que apresentam concentração regional. Quando o critério é dado pela renda, a formação de grupos é simplesmente explicada pelo nível de renda, tanto para Unidades da Federação como para atividades econômicas. 
Quanto aos encontros e desencontros da população ocupada e da renda, principal preocupação deste trabalho, os desencontros são muito mais frequentes que os encontros. Analisando-se a população ocupada e a renda nas Unidades da Federação (Figura 2), os encontros ocorrem nos estados de São Paulo, Rio de Janeiro, Paraná e Rio Grande do Sul, resultado esperado, apontando para o sudeste e sul do país. Mas, observando a ocupação com mais detalhe, isto é, levando-se em conta as diferentes atividades econômicas em cada Unidade da Federação (Quadro 7), os raros encontros ocorrem surpreendentemente nas regiões Norte e Nordeste. Focalizando exatamente as Unidades da Federação do Norte e do Nordeste onde ocorrem esses encontros, são destacadas as atividades de "Administração pública" e "Educação, saúde, serviços sociais". Estas são atividades fortemente ligadas aos serviços públicos, mostrando a importância econômica da presença do Estado nas regiões mais pobres do Brasil.

Como conclusão global do trabalho, pode-se afirmar que algo de invariante é observado, quando analisadas ocupação e renda sob diversos pontos de vista: a desigualdade. Acreditamos que não seria exagero afirmar que este fenômeno, sempre presente, forneceria a estrutura explicativa da sociedade brasileira. Por fim, é interessante lembrar que mesmo as desigualdades de renda, as mais estudadas e divulgadas nos diversos meios de comunicação, são desconhecidas, ao menos na sua real dimensão, mesmo por parcelas bastante esclarecidas da população, conforme ficou bem ilustrado por Rocha e Urani (2005), que puderam afirmar ao final de suas pesquisas:

... apresentaram-se evidências empíricas de que os brasileiros, apesar de indicarem o Brasil como um país qualitativamente desigual, em grande medida, parecem desconhecer o real formato da distribuição de renda no país em que vivem e seu efetivo e elevado grau de desigualdade.

Neste sentido, espera-se que este trabalho contribua para tornar mais conhecidas as fortes desigualdades regionais, ocupacionais e de rendimentos no país.

\section{Referências bibliográficas}

FERREIRA, F. G. H.; LEITE, P. G.; LITCHFIELD, J. A.; ULYSSEA, G. Ascensão e queda da desigualdade de renda no Brasil. Econômica, Rio de Janeiro, v. 8, n. 1, jun. 2006.

HOFFMANN, R. Transferências de renda e redução da desigualdade no Brasil e cinco regiões entre 1997 e 2004. Econômica, Rio de Janeiro, v. 8, n. 1, jun. 2006.

; NEY, M. G. A recente queda da desigualdade de renda no Brasil: análise de

dados da PNAD, do Censo Demográfico e das Contas Nacionais. Econômica, Rio de Janeiro, v. 10, n. 1, jun. 2008. 
A população ocupada e a renda no Brasil: encontros e desencontros

KUBRUSLY, L.; SABOIA, J. Uma análise multivariada da população ocupada nas Regiões Metropolitanas Brasileiras. Ensaios FEE, Porto Alegre, v. 27, n. 2, out. 2006.

MINGOTI, S. A. Análise de dados através de métodos de estatística multivariada - uma abordagem aplicada. Belo Horizonte: Editora UFMG, 2007.

PESQUISA ANUAL DO COMÉRCIO (PAC/IBGE), Rio de Janeiro, IBGE, v. 18, 2006.

PESQUISA NACIONAL POR AMOSTRA DE DOMICÍLIO 2007 (PNAD/IBGE): Unidades da Federação. Rio de Janeiro, IBGE, 2008.

PEROBElli, F. S.; ALMEIDA, E. S.; ALVIM, M. I. S. A.; FERREIRE, P. G. C. Produtividade do setor agrícola brasileiro (1991-2003): uma análise espacial. Nova Economia, Belo Horizonte, v. 17, n. 1, jan./abr. 2007.

ROCHA, R.; URANI, A. Distribuição de renda no Brasil: um ensaio sobre a desigualdade desconhecida. In: ENCONTRO NACIONAL DE ECONOMIA, 33, 2005. Anais... Natal: RN: ANPEC, 2005.

SABOIA, J.; KUBRUSLY, L. Diferenciais regionais e setoriais na indústria brasileira. Economia Aplicada, São Paulo, v. 12, n. 1, jan./mar. 2008.

SPSS, Base, version 16.0: Applications Guide. Chicago, SPSS. Inc, 2008. 
Lucia Silva Kubrusly

\section{Anexo 1}

Proporção da população ocupada por atividade em cada UF e Brasil

\begin{tabular}{|c|c|c|c|c|c|c|c|c|c|c|c|c|}
\hline UF & 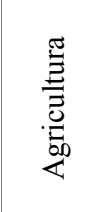 & 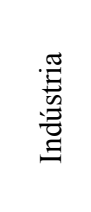 & 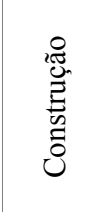 & 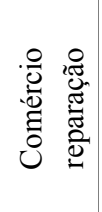 & $\begin{array}{l}\frac{O}{1} \\
\frac{0}{0} \\
\frac{\mathbb{E}}{\frac{0}{4}}\end{array}$ & 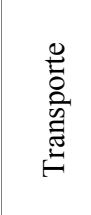 & 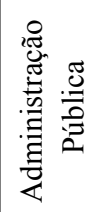 & 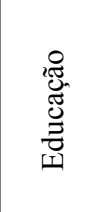 & 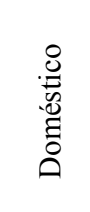 & 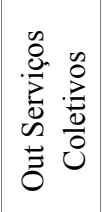 & 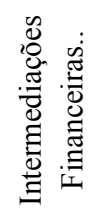 & 吾 \\
\hline RO & 0,307 & 0,115 & 0,065 & 0,162 & 0,034 & 0,026 & 0,077 & 0,078 & 0,061 & 0,030 & 0,045 & 1,000 \\
\hline $\mathrm{AC}$ & 0,264 & 0,124 & 0,060 & 0,135 & 0,024 & 0,031 & 0,104 & 0,122 & 0,058 & 0,037 & 0,041 & 1,000 \\
\hline $\mathrm{AM}$ & 0,210 & 0,138 & 0,072 & 0,171 & 0,050 & 0,057 & 0,057 & 0,090 & 0,058 & 0,031 & 0,065 & 1,000 \\
\hline RR & 0,227 & 0,076 & 0,062 & 0,181 & 0,022 & 0,030 & 0,127 & 0,105 & 0,068 & 0,041 & 0,061 & 1,000 \\
\hline PA & 0,194 & 0,149 & 0,072 & 0,212 & 0,038 & 0,048 & 0,057 & 0,078 & 0,074 & 0,038 & 0,041 & 1,000 \\
\hline AP & 0,069 & 0,073 & 0,098 & 0,233 & 0,039 & 0,048 & 0,097 & 0,141 & 0,094 & 0,042 & 0,065 & 1,000 \\
\hline TO & 0,300 & 0,068 & 0,073 & 0,158 & 0,041 & 0,026 & 0,077 & 0,104 & 0,083 & 0,030 & 0,038 & 1,000 \\
\hline MA & 0,398 & 0,067 & 0,061 & 0,173 & 0,021 & 0,026 & 0,042 & 0,089 & 0,068 & 0,025 & 0,030 & 1,000 \\
\hline PI & 0,423 & 0,072 & 0,056 & 0,154 & 0,021 & 0,026 & 0,046 & 0,083 & 0,061 & 0,037 & 0,020 & 1,000 \\
\hline $\mathrm{CE}$ & 0,290 & 0,161 & 0,055 & 0,168 & 0,037 & 0,032 & 0,036 & 0,076 & 0,069 & 0,031 & 0,044 & 1,000 \\
\hline $\mathrm{RN}$ & 0,231 & 0,123 & 0,065 & 0,196 & 0,040 & 0,038 & 0,056 & 0,100 & 0,062 & 0,041 & 0,048 & 1,000 \\
\hline PB & 0,274 & 0,117 & 0,065 & 0,162 & 0,029 & 0,039 & 0,067 & 0,093 & 0,076 & 0,039 & 0,040 & 1,000 \\
\hline PE & 0,290 & 0,100 & 0,057 & 0,176 & 0,037 & 0,049 & 0,049 & 0,079 & 0,064 & 0,037 & 0,062 & 1,000 \\
\hline $\mathrm{AL}$ & 0,370 & 0,076 & 0,050 & 0,153 & 0,019 & 0,041 & 0,074 & 0,077 & 0,069 & 0,030 & 0,039 & 1,000 \\
\hline $\mathrm{SE}$ & 0,209 & 0,130 & 0,063 & 0,183 & 0,028 & 0,049 & 0,068 & 0,112 & 0,064 & 0,039 & 0,056 & 1,000 \\
\hline BA & 0,354 & 0,076 & 0,062 & 0,151 & 0,039 & 0,041 & 0,045 & 0,077 & 0,071 & 0,033 & 0,050 & 1,000 \\
\hline MG & 0,197 & 0,162 & 0,078 & 0,170 & 0,035 & 0,046 & 0,045 & 0,087 & 0,083 & 0,040 & 0,057 & 1,000 \\
\hline ES & 0,212 & 0,143 & 0,070 & 0,178 & 0,031 & 0,044 & 0,061 & 0,092 & 0,071 & 0,039 & 0,060 & 1,000 \\
\hline RJ & 0,021 & 0,128 & 0,082 & 0,195 & 0,053 & 0,071 & 0,062 & 0,122 & 0,091 & 0,066 & 0,110 & 1,000 \\
\hline SP & 0,050 & 0,216 & 0,065 & 0,193 & 0,040 & 0,057 & 0,040 & 0,105 & 0,077 & 0,046 & 0,113 & 1,000 \\
\hline PR & 0,174 & 0,163 & 0,070 & 0,189 & 0,036 & 0,049 & 0,042 & 0,097 & 0,071 & 0,037 & 0,071 & 1,000 \\
\hline $\mathrm{SC}$ & 0,184 & 0,209 & 0,059 & 0,188 & 0,031 & 0,048 & 0,046 & 0,084 & 0,050 & 0,030 & 0,070 & 1,000 \\
\hline $\mathrm{RS}$ & 0,222 & 0,190 & 0,060 & 0,162 & 0,025 & 0,047 & 0,044 & 0,079 & 0,065 & 0,037 & 0,069 & 1,000 \\
\hline MS & 0,185 & 0,111 & 0,078 & 0,195 & 0,039 & 0,038 & 0,068 & 0,089 & 0,098 & 0,045 & 0,054 & 1,000 \\
\hline MT & 0,288 & 0,115 & 0,069 & 0,168 & 0,040 & 0,037 & 0,055 & 0,071 & 0,073 & 0,028 & 0,056 & 1,000 \\
\hline GO & 0,154 & 0,141 & 0,086 & 0,189 & 0,039 & 0,049 & 0,059 & 0,085 & 0,088 & 0,046 & 0,064 & 1,000 \\
\hline DF & 0,012 & 0,051 & 0,057 & 0,189 & 0,051 & 0,053 & 0,139 & 0,121 & 0,098 & 0,059 & 0,170 & 1,000 \\
\hline $\mathrm{BR}$ & 0,183 & 0,153 & 0,067 & 0,18 & 0,037 & 0,048 & 0,05 & 0,093 & 0,074 & 0,041 & 0,074 & 1,000 \\
\hline
\end{tabular}




\section{Anexo 2}

Proporção da população ocupada por UF em cada atividade

\begin{tabular}{|c|c|c|c|c|c|c|c|c|c|c|c|c|}
\hline UF & 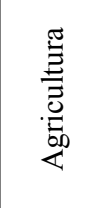 & 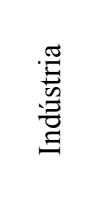 & 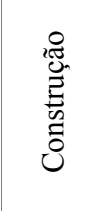 & 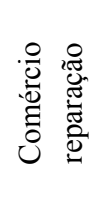 & 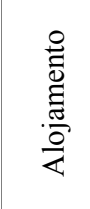 & 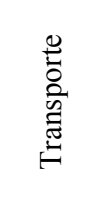 & 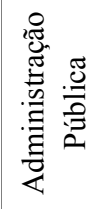 & 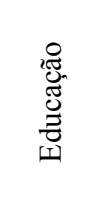 & 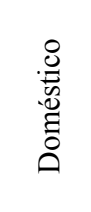 & 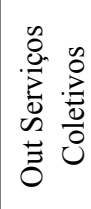 & 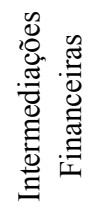 & $\begin{array}{l}\overline{\tilde{g}} \\
\bar{m}\end{array}$ \\
\hline RO & 0,014 & 0,006 & 0,008 & 0,008 & 0,008 & 0,005 & 0,013 & 0,007 & 0,007 & 0,006 & 0,005 & 0,009 \\
\hline $\mathrm{AC}$ & 0,005 & 0,003 & 0,003 & 0,003 & 0,002 & 0,002 & 0,007 & 0,004 & 0,003 & 0,003 & 0,002 & 0,003 \\
\hline $\mathrm{AM}$ & 0,017 & 0,013 & 0,016 & 0,014 & 0,02 & 0,018 & 0,017 & 0,014 & 0,012 & 0,011 & 0,013 & 0,015 \\
\hline RR & 0,003 & 0,001 & 0,002 & 0,002 & 0,001 & 0,001 & 0,006 & 0,002 & 0,002 & 0,002 & 0,002 & 0,002 \\
\hline PA & 0,037 & 0,034 & 0,037 & 0,041 & 0,037 & 0,035 & 0,04 & 0,029 & 0,035 & 0,032 & 0,019 & 0,035 \\
\hline AP & 0,001 & 0,001 & 0,004 & 0,004 & 0,003 & 0,003 & 0,005 & 0,004 & 0,004 & 0,003 & 0,002 & 0,003 \\
\hline TO & 0,012 & 0,003 & 0,008 & 0,007 & 0,008 & 0,004 & 0,011 & 0,008 & 0,008 & 0,005 & 0,004 & 0,007 \\
\hline MA & 0,069 & 0,014 & 0,029 & 0,031 & 0,019 & 0,017 & 0,027 & 0,031 & 0,029 & 0,019 & 0,013 & 0,032 \\
\hline PI & 0,04 & 0,008 & 0,014 & 0,015 & 0,01 & 0,009 & 0,016 & 0,016 & 0,014 & 0,016 & 0,005 & 0,017 \\
\hline $\mathrm{CE}$ & 0,067 & 0,045 & 0,035 & 0,04 & 0,043 & 0,028 & 0,031 & 0,035 & 0,04 & 0,032 & 0,025 & 0,043 \\
\hline $\mathrm{RN}$ & 0,02 & 0,013 & 0,015 & 0,017 & 0,017 & 0,012 & 0,017 & 0,017 & 0,013 & 0,016 & 0,01 & 0,016 \\
\hline PB & 0,026 & 0,013 & 0,017 & 0,015 & 0,014 & 0,014 & 0,023 & 0,017 & 0,018 & 0,016 & 0,009 & 0,017 \\
\hline PE & 0,063 & 0,026 & 0,034 & 0,039 & 0,04 & 0,04 & 0,039 & 0,034 & 0,034 & 0,036 & 0,033 & 0,040 \\
\hline $\mathrm{AL}$ & 0,028 & 0,007 & 0,01 & 0,012 & 0,007 & 0,012 & 0,021 & 0,012 & 0,013 & 0,011 & 0,008 & 0,014 \\
\hline $\mathrm{SE}$ & 0,012 & 0,009 & 0,01 & 0,01 & 0,008 & 0,01 & 0,014 & 0,012 & 0,009 & 0,01 & 0,008 & 0,010 \\
\hline BA & 0,138 & 0,035 & 0,066 & 0,06 & 0,076 & 0,061 & 0,065 & 0,059 & 0,068 & 0,058 & 0,049 & 0,071 \\
\hline MG & 0,117 & 0,115 & 0,126 & 0,103 & 0,102 & 0,103 & 0,097 & 0,102 & 0,121 & 0,105 & 0,084 & 0,108 \\
\hline ES & 0,022 & 0,018 & 0,02 & 0,018 & 0,016 & 0,017 & 0,023 & 0,019 & 0,018 & 0,018 & 0,015 & 0,019 \\
\hline $\mathrm{RJ}$ & 0,009 & 0,064 & 0,093 & 0,083 & 0,11 & 0,112 & 0,096 & 0,101 & 0,094 & 0,125 & 0,114 & 0,077 \\
\hline SP & 0,061 & 0,318 & 0,216 & 0,241 & 0,243 & 0,265 & 0,179 & 0,253 & 0,232 & 0,253 & 0,345 & 0,225 \\
\hline PR & 0,058 & 0,066 & 0,064 & 0,065 & 0,059 & 0,063 & 0,052 & 0,064 & 0,058 & 0,055 & 0,059 & 0,061 \\
\hline $\mathrm{SC}$ & 0,037 & 0,05 & 0,032 & 0,038 & 0,031 & 0,037 & 0,034 & 0,033 & 0,025 & 0,027 & 0,035 & 0,037 \\
\hline $\mathrm{RS}$ & 0,079 & 0,081 & 0,058 & 0,059 & 0,045 & 0,063 & 0,057 & 0,055 & 0,057 & 0,058 & 0,061 & 0,065 \\
\hline MS & 0,013 & 0,009 & 0,015 & 0,014 & 0,014 & 0,01 & 0,018 & 0,013 & 0,017 & 0,014 & 0,01 & 0,013 \\
\hline MT & 0,025 & 0,012 & 0,016 & 0,015 & 0,017 & 0,012 & 0,017 & 0,012 & 0,015 & 0,011 & 0,012 & 0,016 \\
\hline GO & 0,027 & 0,03 & 0,041 & 0,034 & 0,034 & 0,033 & 0,038 & 0,03 & 0,038 & 0,036 & 0,028 & 0,032 \\
\hline DF & 0,001 & 0,004 & 0,011 & 0,013 & 0,018 & 0,014 & 0,036 & 0,017 & 0,017 & 0,018 & 0,029 & 0,013 \\
\hline Total & 1,000 & 1,000 & 1,000 & 1,000 & 1,000 & 1,000 & 1,000 & 1,000 & 1,000 & 1,000 & 1,000 & 1,000 \\
\hline
\end{tabular}




\section{Anexo 3}

Renda Mensal Média (em salários mínimos) por Unidade da Federação e por Atividade Econômica

\begin{tabular}{|c|c|c|c|c|c|c|c|c|c|c|c|c|}
\hline UF & 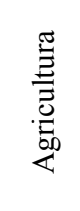 & 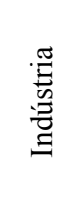 & 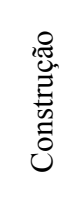 & 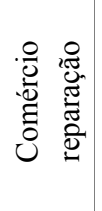 & 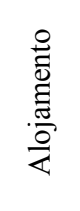 & 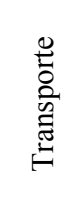 & 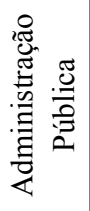 & 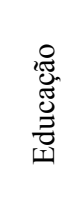 & 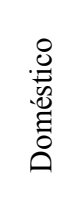 & $\begin{array}{ccc}n & 0 \\
0 & 0 & 0 \\
0 & 0 & 0 \\
3 & 0 & 0 \\
0 & 0 & 0 \\
0 & 0\end{array}$ & 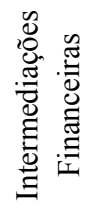 & 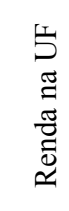 \\
\hline RO & 1,69 & 2,04 & 1,88 & 2,20 & 1,77 & 2,76 & 3,84 & 3,03 & 0,72 & 1,89 & 3,35 & 2,19 \\
\hline $\mathrm{AC}$ & 1,04 & 1,68 & 1,65 & 2,00 & 1,87 & 2,93 & 4,49 & 3,11 & 0,64 & 2,14 & 2,72 & 2,42 \\
\hline AM & 1,33 & 2,18 & 1,95 & 2,33 & 2,01 & 2,62 & 3,54 & 2,51 & 0,87 & 2,08 & 3,05 & 2,23 \\
\hline $\mathrm{RR}$ & 1,09 & 1,87 & 1,86 & 1,63 & 1,64 & 2,46 & 3,50 & 2,87 & 0,90 & 1,66 & 2,36 & 1,99 \\
\hline PA & 1,38 & 1,96 & 1,72 & 1,77 & 1,63 & 2,47 & 2,91 & 2,35 & 0,64 & 1,65 & 2,89 & 1,91 \\
\hline AP & 1,30 & 2,37 & 1,56 & 2,13 & 1,70 & 2,25 & 4,38 & 3,31 & 0,81 & 1,58 & 2,66 & 2,38 \\
\hline TO & 1,31 & 1,75 & 1,67 & 2,10 & 1,47 & 1,99 & 3,11 & 2,23 & 0,53 & 1,73 & 3,06 & 2,02 \\
\hline MA & 1,03 & 1,62 & 1,57 & 1,77 & 1,19 & 1,86 & 2,53 & 1,74 & 0,48 & 1,66 & 2,16 & 1,53 \\
\hline PI & 0,45 & 1,44 & 1,10 & 1,38 & 1,27 & 1,68 & 2,96 & 2,05 & 0,48 & 1,25 & 2,69 & 1,44 \\
\hline $\mathrm{CE}$ & 0,55 & 1,24 & 1,35 & 1,61 & 1,25 & 2,27 & 2,95 & 1,95 & 0,58 & 1,51 & 2,38 & 1,46 \\
\hline RN & 0,81 & 1,77 & 1,63 & 1,59 & 1,36 & 1,89 & 3,05 & 2,22 & 0,57 & 1,28 & 2,21 & 1,82 \\
\hline PB & 0,75 & 1,31 & 1,08 & 1,68 & 1,20 & 1,79 & 2,93 & 2,16 & 0,54 & 1,1 & 2,78 & 1,72 \\
\hline PE & 0,82 & 1,67 & 1,33 & 1,64 & 1,35 & 1,85 & 2,83 & 2,02 & 0,64 & 1,33 & 2,42 & 1,63 \\
\hline $\mathrm{AL}$ & 0,81 & 1,37 & 1,41 & 1,64 & 1,19 & 2,24 & 2,86 & 1,91 & 0,60 & 1,44 & 2,69 & 1,76 \\
\hline SE & 0,79 & 1,58 & 1,53 & 1,57 & 1,05 & 2,23 & 3,31 & 2,10 & 0,63 & 1,3 & 2,35 & 1,76 \\
\hline BA & 0,86 & 1,82 & 1,57 & 1,30 & 1,36 & 2,04 & 2,62 & 2,20 & 0,55 & 1,37 & 2,62 & 1,6 \\
\hline $\mathrm{MG}$ & 1,47 & 2,26 & 1,94 & 2,21 & 1,80 & 2,97 & 3,20 & 2,65 & 0,78 & 1,82 & 3,02 & 2,23 \\
\hline ES & 1,78 & 2,45 & 2,23 & 2,34 & 1,73 & 3,02 & 3,10 & 2,54 & 0,84 & 2,03 & 3,10 & 2,45 \\
\hline RJ & 1,26 & 2,89 & 2,29 & 2,43 & 2,18 & 3,23 & 4,50 & 3,19 & 1,20 & 2,50 & 3,65 & 2,99 \\
\hline SP & 2,11 & 3,12 & 2,59 & 2,96 & 2,35 & 3,64 & 4,12 & 3,50 & 1,22 & 2,81 & 3,82 & 3,2 \\
\hline PR & 2,45 & 2,57 & 2,26 & 2,50 & 2,18 & 3,43 & 3,78 & 3,09 & 0,98 & 2,55 & 3,76 & 2,86 \\
\hline $\mathrm{SC}$ & 2,22 & 2,71 & 3,02 & 2,97 & 2,42 & 3,47 & 4,23 & 3,55 & 1,19 & 2,46 & 3,75 & 2,97 \\
\hline $\mathrm{RS}$ & 2,12 & 2,38 & 2,13 & 2,57 & 2,16 & 3,30 & 3,72 & 3,15 & 1,01 & 2,44 & 3,56 & 2,65 \\
\hline MS & 2,19 & 2,00 & 1,93 & 2,33 & 1,87 & 3,04 & 4,10 & 3,31 & 0,78 & 1,98 & 3,42 & 2,71 \\
\hline MT & 2,12 & 2,13 & 2,26 & 2,58 & 2,12 & 3,24 & 3,35 & 3,01 & 0,78 & 1,94 & 3,61 & 2,46 \\
\hline GO & 2,02 & 2,42 & 2,14 & 2,33 & 2,12 & 2,87 & 3,57 & 2,90 & 0,85 & 2,05 & 2,95 & 2,49 \\
\hline DF & 2,57 & 3,19 & 2,51 & 2,96 & 2,54 & 3,87 & 7,36 & 5,40 & 1,23 & 3,18 & 4,35 & 5,19 \\
\hline $\mathrm{BR}$ & 1,74 & 2,65 & 2,14 & 2,49 & 2,03 & 3,21 & 4,09 & 3,13 & 0,91 & 2,31 & 3,82 & 2,48 \\
\hline
\end{tabular}

Elaboração própria a partir dos dados da PNAD (2007). 